\title{
WestVirginiaUniversity
}

THE RESEARCH REPOSITORY @ WVU

Graduate Theses, Dissertations, and Problem Reports

2010

\section{Permeability of hot mix asphalt concrete as affected by binder content}

Joseph A. Giompalo

West Virginia University

Follow this and additional works at: https://researchrepository.wvu.edu/etd

\section{Recommended Citation}

Giompalo, Joseph A., "Permeability of hot mix asphalt concrete as affected by binder content" (2010). Graduate Theses, Dissertations, and Problem Reports. 2098.

https://researchrepository.wvu.edu/etd/2098

This Thesis is protected by copyright and/or related rights. It has been brought to you by the The Research Repository @ WVU with permission from the rights-holder(s). You are free to use this Thesis in any way that is permitted by the copyright and related rights legislation that applies to your use. For other uses you must obtain permission from the rights-holder(s) directly, unless additional rights are indicated by a Creative Commons license in the record and/ or on the work itself. This Thesis has been accepted for inclusion in WVU Graduate Theses, Dissertations, and Problem Reports collection by an authorized administrator of The Research Repository @ WVU. For more information, please contact researchrepository@mail.wvu.edu. 
Permeability of Hot Mix Asphalt Concrete as Affected by Binder Content

\title{
Joseph A. Giompalo
}

Thesis submitted to the College of Engineering and Mineral Resources at West Virginia University in partial fulfillment of the requirements for the degree of

\author{
Master of Science
}

In

Civil Engineering

\author{
John P. Zaniewski, Ph.D., Chair \\ Darrell R. Dean, Ph.D. \\ Indrajit Ray, Ph.D. \\ Department of Civil Engineering
}

Morgantown, West Virginia

2010

Keywords: Asphalt Pavements, Permeability, Porosity, Air Voids, Binder Content, Density 


\title{
ABSTRACT \\ Permeability of Hot Mix Asphalt Concrete as Affected by Binder Content
}

\author{
Joseph A. Giompalo
}

One of the primary objectives when constructing hot mix asphalt concrete (HMAC) is achieving the target density in order for the pavement to be impermeable. If the density is too low, water infiltration causes pavement damage from freeze-thaw and other effects caused by the presence of water. If the pavement density is too high, rutting, flushing, and shoving will occur.

This research used the Florida Method of Test for Measurement of Water Permeability of Compacted Asphalt Paving Mixtures to examine how permeability is affected by binder content and compaction level. Asphalt samples containing 5.2, 5.7, 6.2 , and 6.7 percent binder at air void levels of $4,6,8$, and 10 percent were tested in a Florida Department of Transportation (FDOT) style permeameter. Gyratory and indirect tension (IDT) strength test data were also used to evaluate the effect binder has on compaction and rutting resistance.

This research suggests several changes to West Virginia's construction specifications, including permeability testing as part of the mix design process. Changing the maximum air void specifications from 8 to 7 percent is suggested to reduce the possibility of the construction of permeable pavements to reach the threshold where permeability drastically increases. Recommendations are also made for further research. 


\section{ACKNOWLEDGMENTS}

I would like to express my sincere gratitude to Dr. John Zaniewski, my advisor, for his guidance, support, and encouragement during the pursuit of my Master of Science in Civil Engineering degree. Dr. Zaniewski's insight and advice was particularly helpful during my research. I would like to thank Dr. Darrell Dean and Dr. Indrajit Ray for their time and willingness to serve on my committee.

I would also like to thank Armando Orobio for his guidance in the asphalt laboratory and support throughout graduate school. Most of all, I would like to thank my

parents, Joe and Peggy Giompalo, for their love, confidence, encouragement, and support throughout graduate school. You have helped me build the foundation of my life and I cannot thank you enough for everything you have done. 


\section{TABLE OF CONTENTS}

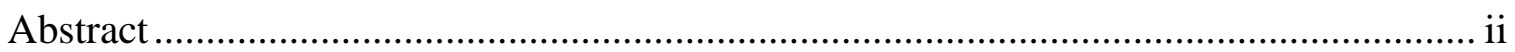

Acknowledgments.................................................................................................. ii

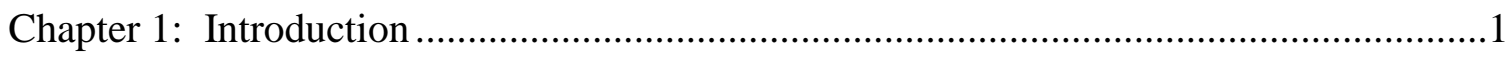

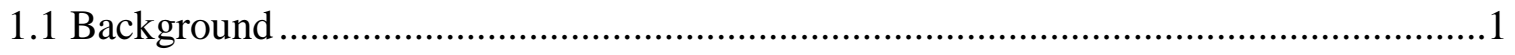

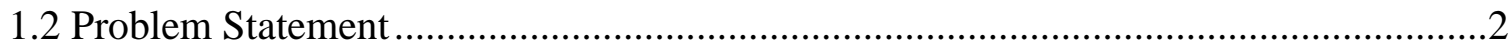

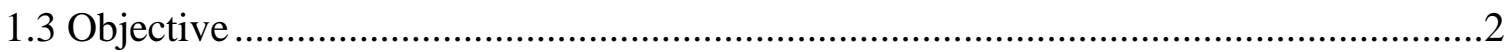

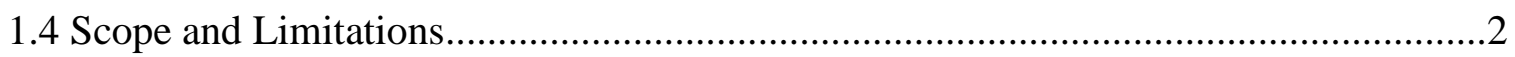

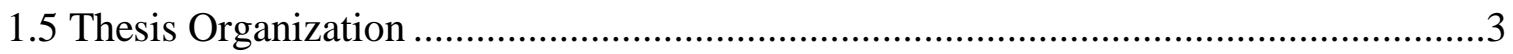

Chapter 2: Literature Review ......................................................................................

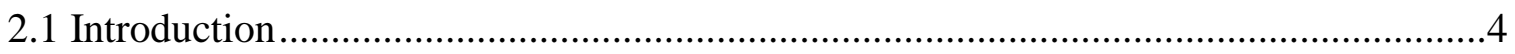

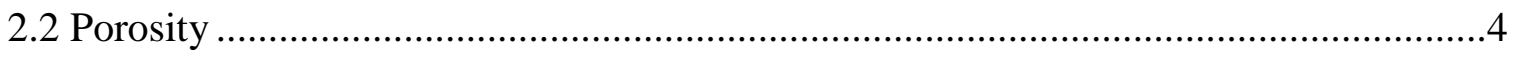

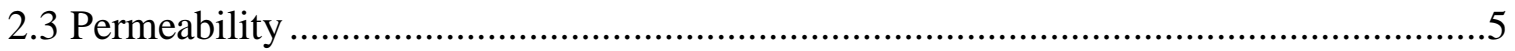

2.4 Factors Affecting Permeability of Pavements .........................................................5

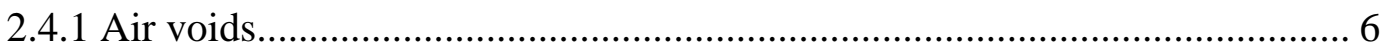

2.4.2 Nominal Maximum Aggregate Size (NMAS) ………………………….... 6

2.4.3 Gradation of aggregates .......................................................................... 7

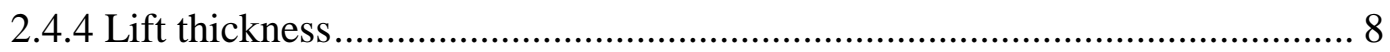

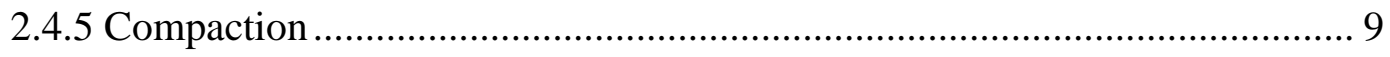

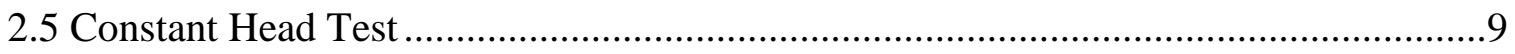

2.6 Falling Head Test …………………………………............................................11

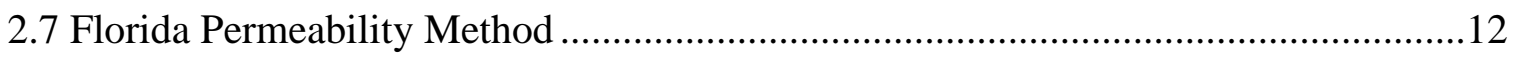

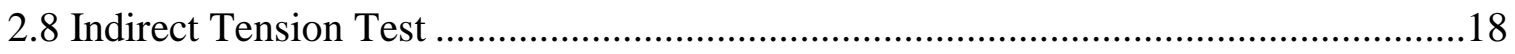

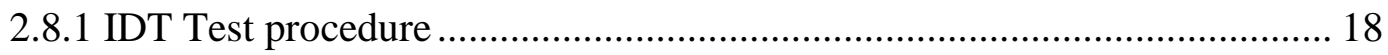




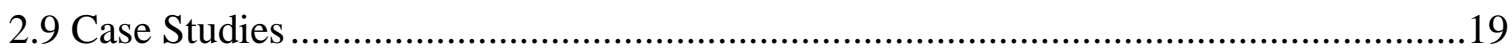

2.9.1 Pennsylvania _.......................................................................................... 19

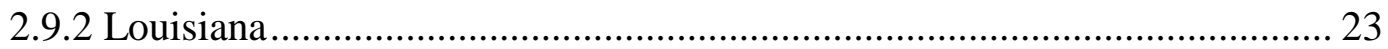

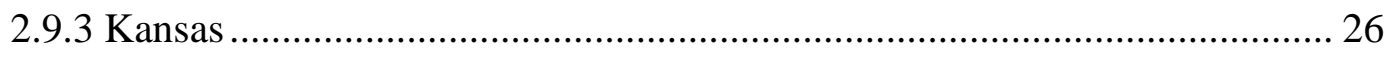

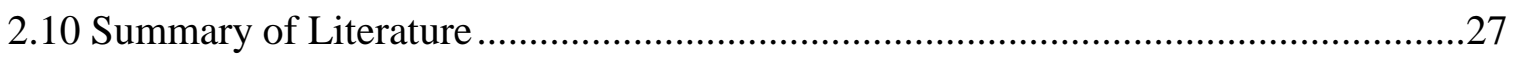

Chapter 3: Research Methodology ……………………………………………….....29

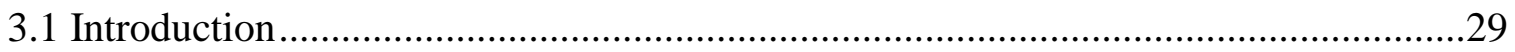

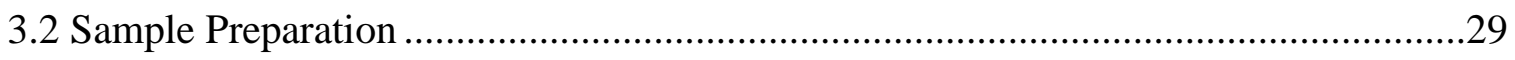

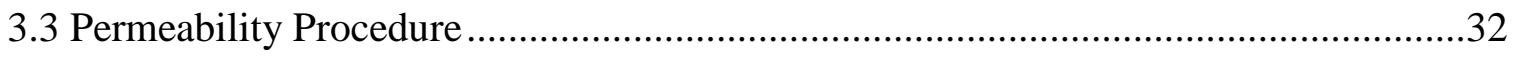

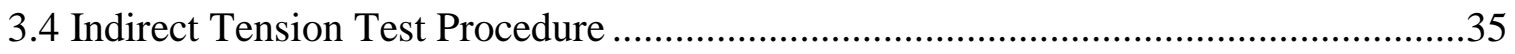

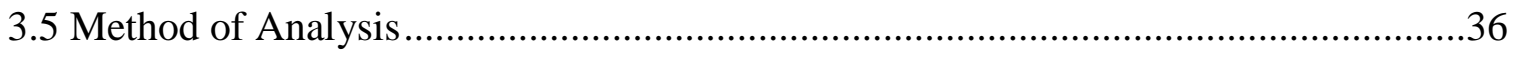

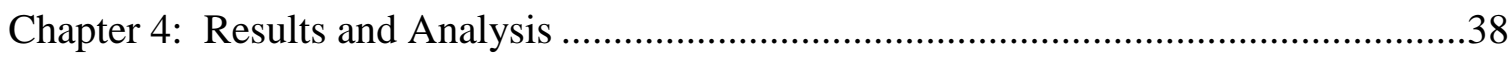

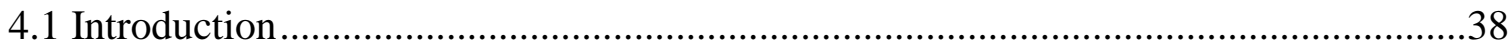

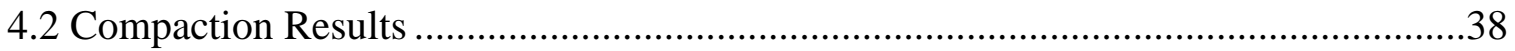

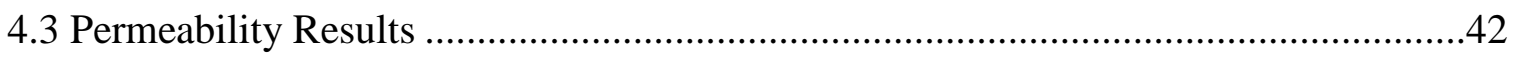

4.4 Indirect Tension Test Results..............................................................................

Chapter 5: Conclusions and Recommendations ………………..................................52

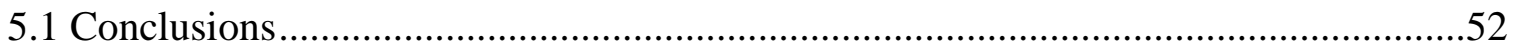

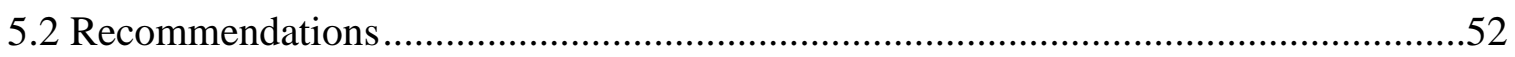

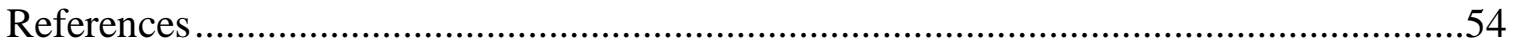




\section{LIST OF FIGURES}

Figure 2.1: Permeability vs. Air Voids for 9.5mm Coarse Mix ...................................6

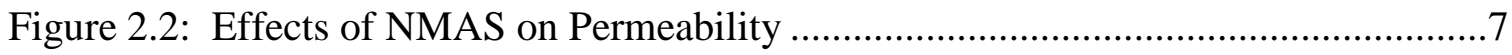

Figure 2.3: Coarse and Fine Graded Gradations .....................................................

Figure 2.4: Permeability vs. Lift Thickness to NMAS ...............................................

Figure 2.5: Constant Head Permeameter ................................................................ 10

Figure 2.6: Falling Head Permeameter ...................................................................... 11

Figure 2.7: Water Permeability Testing Apparatus (Not to Scale) ................................14

Figure 2.8: Field and Laboratory Permeability Values at 7\% VTM..............................27

Figure 3.1: Combined Gradation Used During Research ...........................................31

Figure 3.2: HMAC Permeameter Used During Research..........................................32

Figure 3.3: Asphalt Sample Coated with Petroleum Jelly ...........................................33

Figure 3.4: Asphalt Sample Placed on Lower Pedestal Plate .........................................33

Figure 3.5: Sealing Tube Placed Over Asphalt Sample..............................................34

Figure 3.6: Clamp Assemblies Placed on Graduated Cylinder Plate...............................34

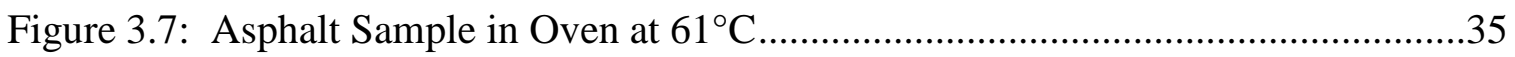

Figure 3.8: Asphalt Sample Placed in IDT Testing Apparatus .....................................36

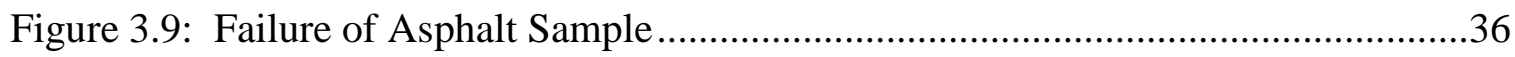

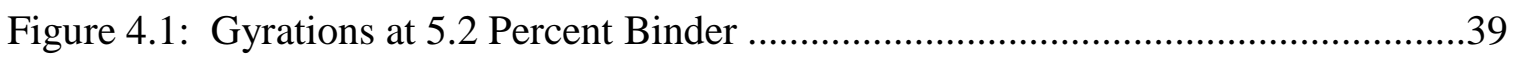

Figure 4.2: Gyrations at 5.7 Percent Binder .................................................... 40

Figure 4.3: Gyrations at 6.2 Percent Binder ....................................................... 40

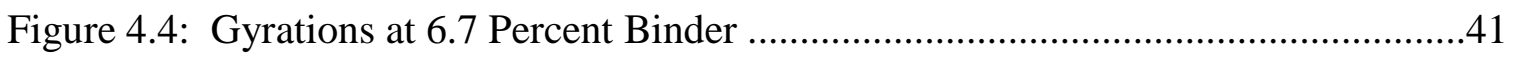

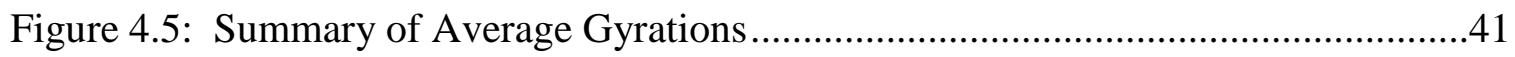

Figure 4.6: Permeability at 5.2 Percent Binder..........................................................43 
Figure 4.7: Permeability at 5.7 Percent Binder...................................................44

Figure 4.8: Permeability at 6.2 Percent Binder .....................................................44

Figure 4.9: Permeability at 6.7 Percent Binder.....................................................

Figure 4.10: Summary of Average Permeability Values ...........................................45

Figure 4.11: Permeability Statistical Analysis Results ............................................46

Figure 4.12: Estimated Maximum Allowable Traffic at 5.2 Percent Binder...................48

Figure 4.13: Estimated Maximum Allowable Traffic at 5.7 Percent Binder...................49

Figure 4.14: Estimated Maximum Allowable Traffic at 6.2 Percent Binder...................49

Figure 4.15: Estimated Maximum Allowable Traffic at 6.7 Percent Binder...................50

Figure 4.16: Summary of Average Estimated Maximum Allowable Traffic ..................50

Figure 4.17: IDT Statistical Analysis Results ......................................................51 


\section{LIST OF TABLES}

Table 2.1: Temperature Correction for Viscosity of Water, Celsius ..............................17

Table 2.2: Visual Observations of Holes at MP 217.65 in Westbound Slow Lane.........21

Table 2.3: Visual Observations of Holes at MP 212.90 in Westbound Slow Lane ..........21

Table 2.4: Density, Moisture, and Saturation Data, MP 217.65 Westbound Slow Lane .22

Table 2.5: Density, Moisture, and Saturation Data, MP 212.90 Westbound Slow Lane .22

Table 2.6: Selection of Model Parameters ....................................................................26

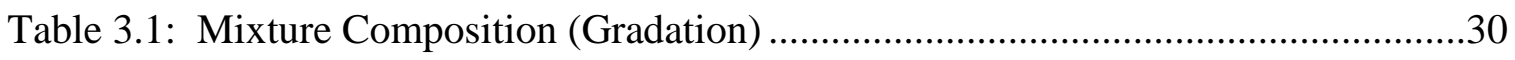

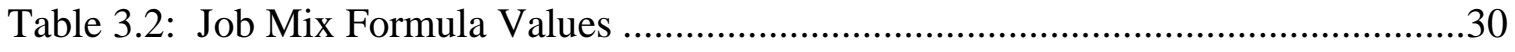

Table 4.1: Gyrations for All Asphalt Samples...........................................................39

Table 4.2: Permeability Results for All Asphalt Samples .........................................43

Table 4.3: Estimated Maximum Allowable Traffic for All Asphalt Samples .................48 


\section{CHAPTER 1: INTRODUCTION}

\subsection{BACKGROUND}

One of the primary objectives when constructing hot mix asphalt concrete (HMAC) pavements is achieving the target density in order for the pavement to be impermeable. If the density is too low, water infiltration causes pavement damage from freeze-thaw and other effects caused by the presence of water. If the pavement density is too high, rutting, flushing, and shoving may occur.

There are many factors that contribute to pavement permeability. Studies have shown that permeability is a function of percent air voids, nominal maximum aggregate size (NMAS), aggregate gradation, lift thickness, and compaction effort.

One of the most important factors that affect permeability of asphalt is air voids; when the percent of air voids increase, permeability also increases. When the air voids reach approximately 8 percent, a dramatic increase in permeability is shown to occur. When air voids remain below 7 percent, permeability does not change significantly. An air void level of 6 percent or less was shown to be impermeable (Zube 1962, Brown et al., 1989).

Permeability is directly related to the nominal maximum aggregate size (NMAS). The size of the air voids increases when the size of the aggregates in a HMAC mix increase. An increase in the size of the air voids will often cause the air voids to become interconnected resulting in an increase in permeability (Mallick et al., 2003).

HMAC aggregate gradation also directly affects permeability. Gradations that fall below the maximum density line (MDL) are considered to be coarse-graded and tend to have high permeability due to interconnected voids. Gradations that are above the maximum density line are considered fine-graded and tend to have low permeability (Hudson et al., 1965).

The permeability of a wearing surface also depends on the lift thickness. A thicker lift is placed to reduce the probability of interconnected voids to form, which allows water to flow into the layers below. The heat from a thicker lift allows the 
aggregates to orientate properly which results in an increase in pavement density and a decrease in permeability (Russel et al., 2004, Musselman et al., 1998).

Compaction is the process in which external forces are used to reduce the volume of air and orientate the aggregates into a denser configuration in an HMAC mixture. The liquid asphalt aides in the compaction process by acting as a lubricant. When the amount of air is reduced, the mixture becomes denser and permeability decreases. The chance for rutting and other problems increases if too much compaction is used (Roberts et al., 1996).

\subsection{PROBLEM STATEMENT}

Previously, there has been adequate research showing the various factors that affect the permeability of HMAC. One factor that has not been widely addressed is how the amount of asphalt binder in a mixture affects the permeability. When the asphalt content in a mixture is increased, the amount of compaction required to achieve lower air void levels is greatly reduced. If too much binder is added, then problems such as rutting will occur. This research focused on finding the asphalt content that maintains low permeability when compacted to a specified density while maintaining adequate rut resistance.

\subsection{OBJECTIVE}

The primary objective of this research is to evaluate how binder content affects the permeability of hot mix asphalt concrete. Also, information regarding how binder content affects compaction and rutting resistance will be documented.

Recommendations can be formulated to change West Virginia's specifications with this information.

\subsection{SCOPE AND LIMITATIONS}

This research focused on making $9.5 \mathrm{~mm}$ skid surface samples that were $75 \mathrm{~mm}$ in height, $150 \mathrm{~mm}$ in diameter, and contained 4, 6, 8, and 10 percent air voids. Samples were then made at each air void level containing 5.2, 5.7, 6.2, and 6.7 percent binder. Gyratory data were documented and analyzed to observe how binder content affected 
compaction effort. Two maximum bulk specific gravity $\left(\mathrm{G}_{\mathrm{mb}}\right)$ samples were made for each combination and were tested using the Florida Method of Test for Measurement of Water Permeability of Compacted Asphalt Paving Mixtures. Once the coefficient of permeability was found for each asphalt specimen, an indirect tension (IDT) test was performed to evaluate potential rut resistance.

Aggregate for making the asphalt specimens was obtained from Greer Industries. Only one gradation was evaluated in this research.

\subsection{THESIS ORGANIZATION}

Chapter 2 describes various factors that affect permeability of hot mix asphalt concrete (HMAC). A case study performed by Auburn University of Pennsylvania pavements in 2001 was reviewed. Two laboratory methods that test the permeability of asphalt specimens are also reviewed. Laboratory and field permeability values are compared from the Kansas Department of Transportation and Louisiana Transportation Research Center (LTRC). Lastly, the Florida permeability test method that was used in this research is reviewed.

Chapter 3 discusses the experimental plan and explains the laboratory test procedures followed during the process of this research.

Chapter 4 presents the results and analysis of this research. Permeability values of asphalt specimens containing 5.2, 5.7, 6.2, and 6.7 percent binder at 4, 6, 8, and 10 percent air voids are compared. The gyratory compaction characteristics of each sample were analyzed to evaluate how binder affects compaction. The results of indirect tension (IDT) test for each sample was analyzed to determine how binder content affects rutting.

Chapter 5 presents conclusions and recommendations for implementing this research and for further research. 


\section{CHAPTER 2: LITERATURE REVIEW}

\subsection{INTRODUCTION}

Permeability of hot mix asphalt concrete (HMAC) has become an important issue since the introduction of SuperPave mixtures in the United States. Adequate air voids must be present in order to prevent permanent deformation such as rutting and shoving, however, high permeability can result in excess amounts of water seeping through the wearing surface, causing moisture damage and oxidation.

There are many factors that affect the permeability of pavements: percent air voids, nominal maximum aggregate size (NMAS), lift thickness, compaction effort, and aggregate gradation. Numerous case studies have been performed to determine how each of these factors affects permeability. Studies have shown that an air void level of 7 to 8 percent causes a rapid increase in permeability (Zube 1962, Brown et al., 1989). The probability for air voids to become interconnected also increases when the NMAS increases, resulting in higher permeability. Coarse gradations commonly fall below the maximum density line (MDL) and have high permeability, even with low in-place air void levels. Fine gradations tend to be above the MDL and have low permeability even at high in-place air void levels (Mallick et al., 1999).

There are two types of methods for testing HMAC permeability: constant head test and falling head test. The falling head test is typically used to test low permeable materials. The Florida permeability test method is a falling head test and is widely used across the United States. (Florida Method of Test for Measurement of Water Permeability of Compacted Asphalt Paving Mixtures) This test method was used for this research.

\subsection{POROSITY}

Porosity is defined as the ratio of the volume of voids to the total volume of material such as soil, sediment, aggregate, or HMAC. The porosity of a material is influenced by various factors: particle shape, particle sorting, and particle size. A material containing particles with rounded edges typically will have high porosity. In 
contrast, a material containing particles that are angular or flat and elongated will have lower porosity provided it can be compacted into a dense configuration. A well sorted material with particles that are approximately the same size will have higher porosity than a material with different sized particles. A mixture containing only large particles will contain greater pore space than a mixture with smaller particles (Lerner et al., 2003).

\subsection{PERMEABILITY}

Permeability is defined as the rate of flow of a liquid or gas through a porous material. Darcy showed that the rate of flow of water was proportional to the hydraulic gradient of a given sample area when the fundamental theory of permeability was established. The hydraulic gradient is defined as the head loss per unit of length. Once water is transmitted through of porous material, the head loss will increase linearly with the velocity of the water, as long as the flow is laminar. The relationship becomes nonlinear and Darcy's Law becomes invalid when the flow of water is turbulent. When measuring permeability, two methods of testing can be used: a constant head test and a falling head test (Cooley, 1999).

\subsection{FACTORS AFFECTING PERMEABILITY OF PAVEMENTS}

Ever since the adoption of the SuperPave mix design method, permeability in HMAC pavements has been a major issue (Mallick et al., 2003). Various studies have been conducted to identify the many factors affecting permeability within pavements. The following is a summary of the factors affecting permeability characteristics from research done across the United States:

- Air Voids

- Nominal Maximum Aggregate Size (NMAS)

- Gradation of Aggregates

- $\quad$ Lift Thickness

- Compaction Effort 


\subsubsection{Air voids}

The most important factor affecting asphalt permeability is air voids. Studies have shown that when air voids increase within a mix, permeability also increases. As the total air void level in a mix (VTM) exceeds 8 percent, permeability has been shown to drastically increase (Ford et al., 1988). There is no significant change in permeability when air void levels are below 7 percent. Researchers have found that an air void level of approximately 6 percent or less is necessary for an impervious coarse-graded mixture (Zube 1962, Brown et al., 1989, Mallick et al., 2003), Figure 2.1.

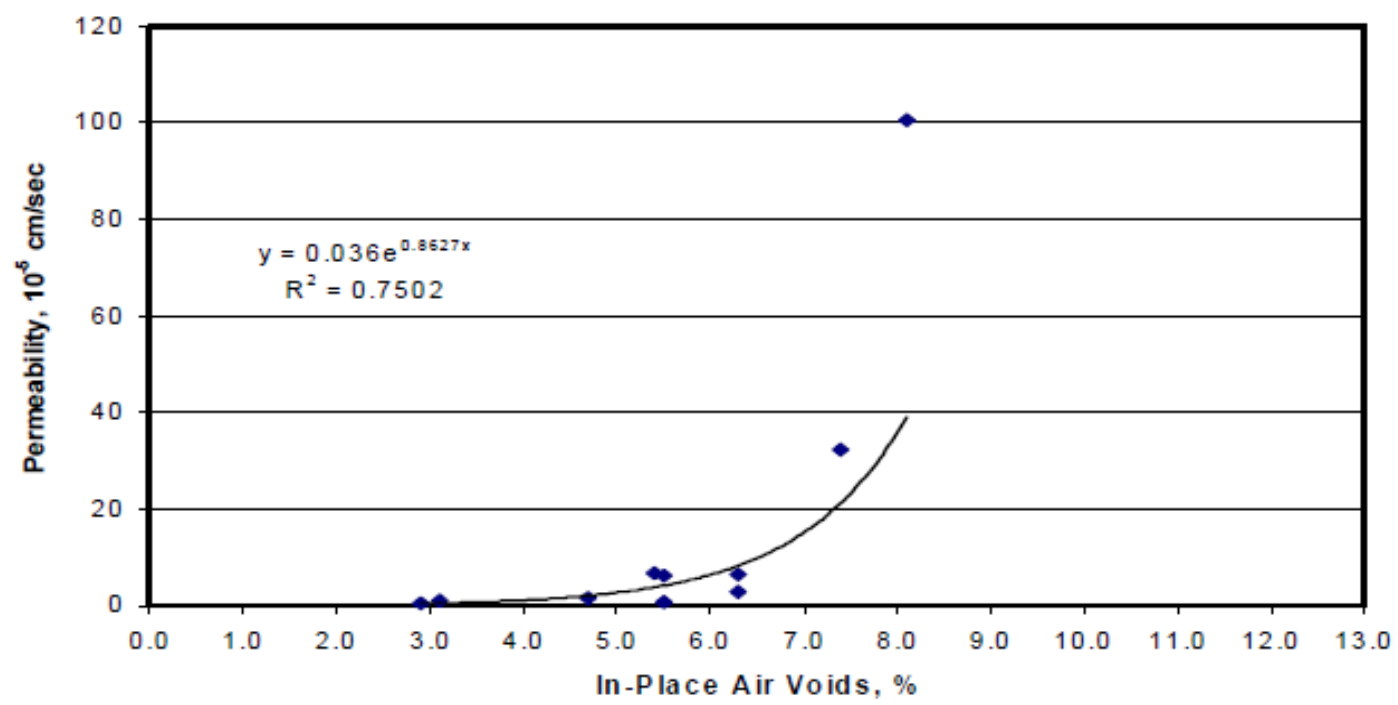

Figure 2.1: Permeability vs. Air Voids for $9.5 \mathrm{~mm}$ Coarse Mix

\subsubsection{Nominal Maximum Aggregate Size (NMAS)}

Permeability of pavements is directly related to the nominal maximum aggregate size. As the size of the aggregates increase, the size of the air voids also increase. This is especially true when dealing with coarse-graded SuperPave mixes. The tendency for the air voids to become interconnected increases when the amount of air voids increase.

Figure 2.2 shows that permeability increases when NMAS increases (Cooley et al., 2002, Mallick et al., 2003). 


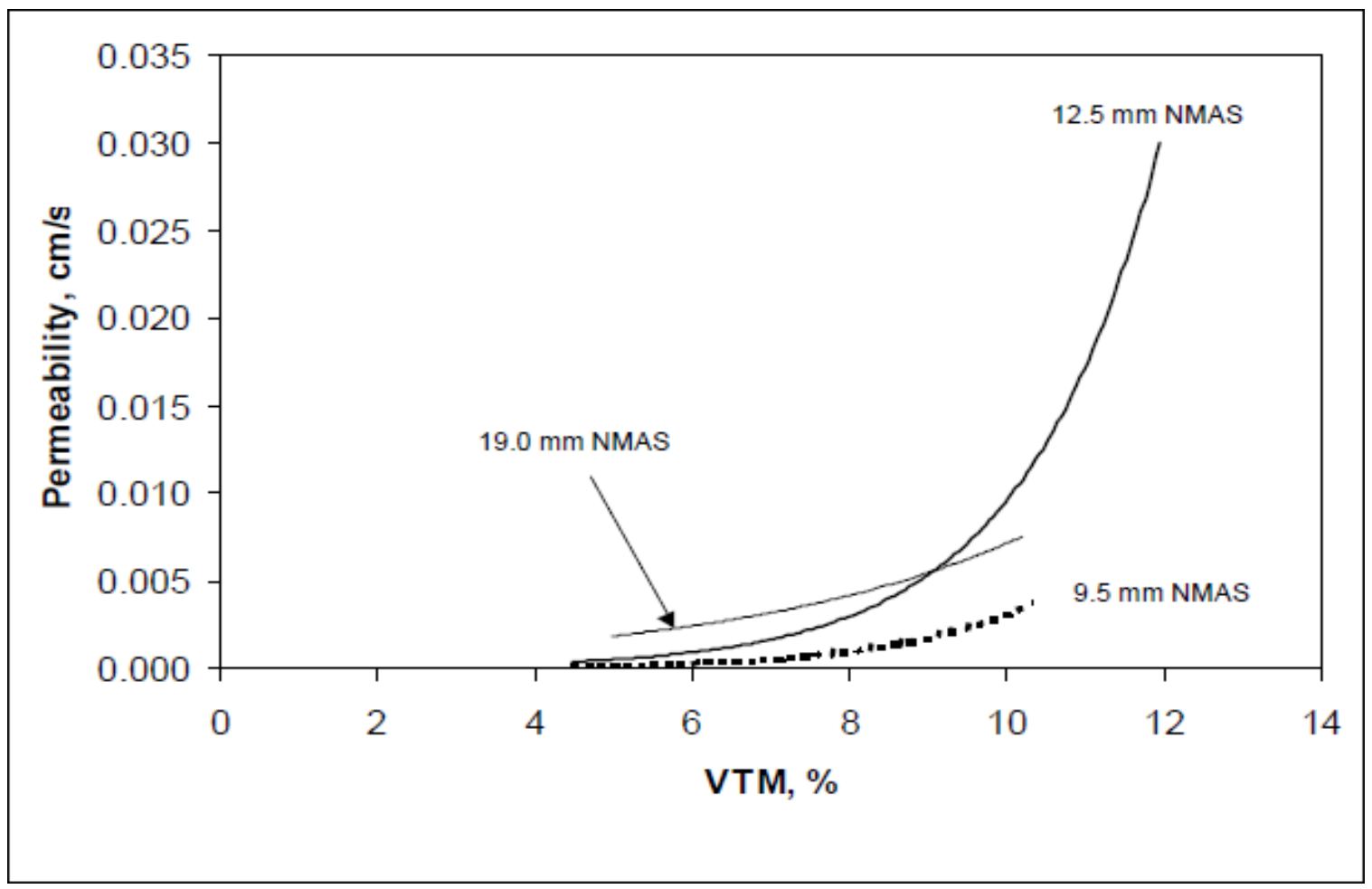

Figure 2.2: Effects of NMAS on Permeability

\subsubsection{Gradation of aggregates}

The mixture's gradation affects permeability characteristics in addition to the size of the aggregates. Gradations that fall below the maximum density line (MDL) are considered coarse gradations and typically have high permeability even at low in-place air void contents. Gradations that are above the MDL are considered fine gradations and tend to be less permeable at low in-place air void contents (Hudson et al., 1965). Gradation affects the size of air voids when compacted. Coarse mixes will have the potential for more interconnected air voids and will result in an increase in permeability. Figure 2.3 shows the difference between coarse and fine graded mixes using a 0.45 power chart (Mohammad et al., 2003). 


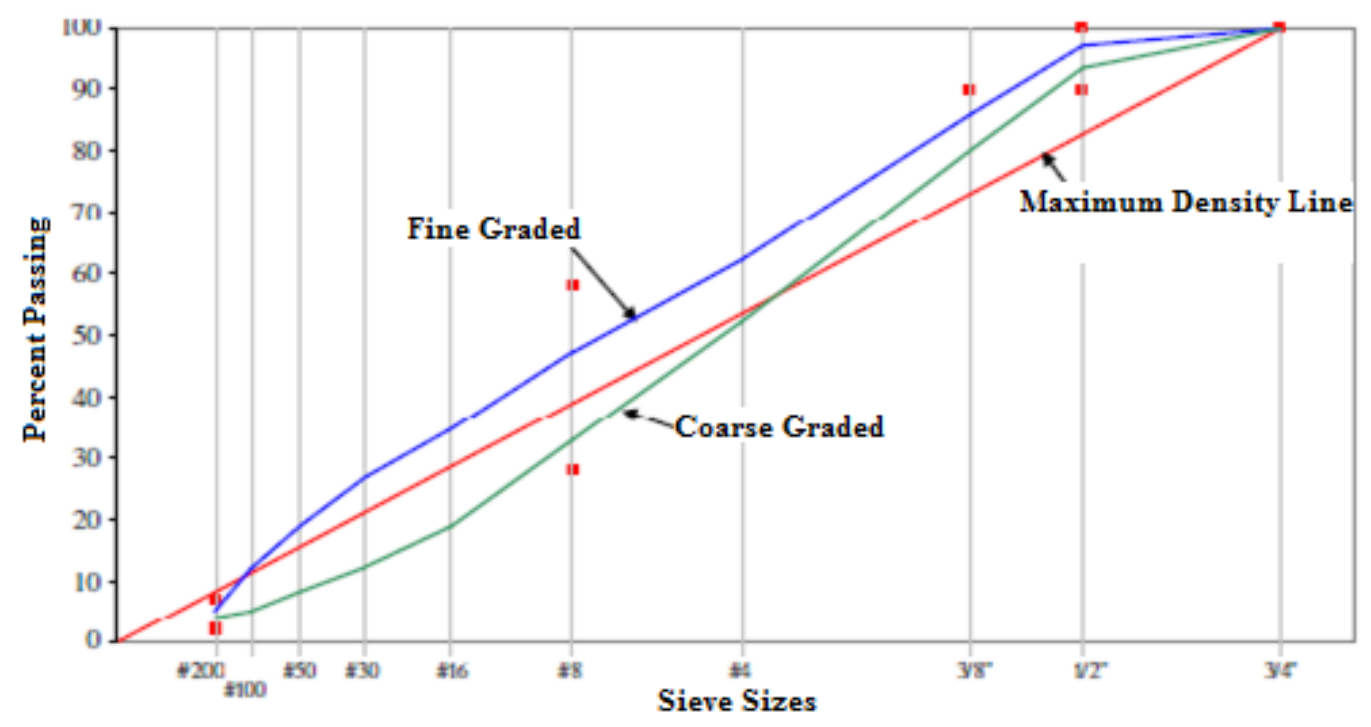

Figure 2.3: Coarse and Fine Graded Gradations

\subsubsection{Lift thickness}

Another factor to take into account when dealing with permeability is asphalt lift thickness. As the lift thickness increases, the chance for interconnected voids, which allow water to flow a sufficient depth deceases. In addition, thicker lifts are used because they are generally easier to compact. When a thick lift is placed, the retained heat in the asphalt keeps its viscosity low which allows the aggregates to orientate properly, resulting in an increased pavement density (Russel et al., 2004, Musselman et al., 1998).

NCAT confirmed that the HMAC lift thickness is directly related to permeability. They have shown that a lift thickness-to-NMAS ratio (t/NMAS) minimum of 3.0 is recommended, but a t/NMAS ratio of 4.0 is preferred. The results of their study show that the lowest permeability values were found with a t/MAS ratio of 4.0. Figure 2.4 shows that when lift thickness increases, permeability decreases (Cooley et al., 2002). 


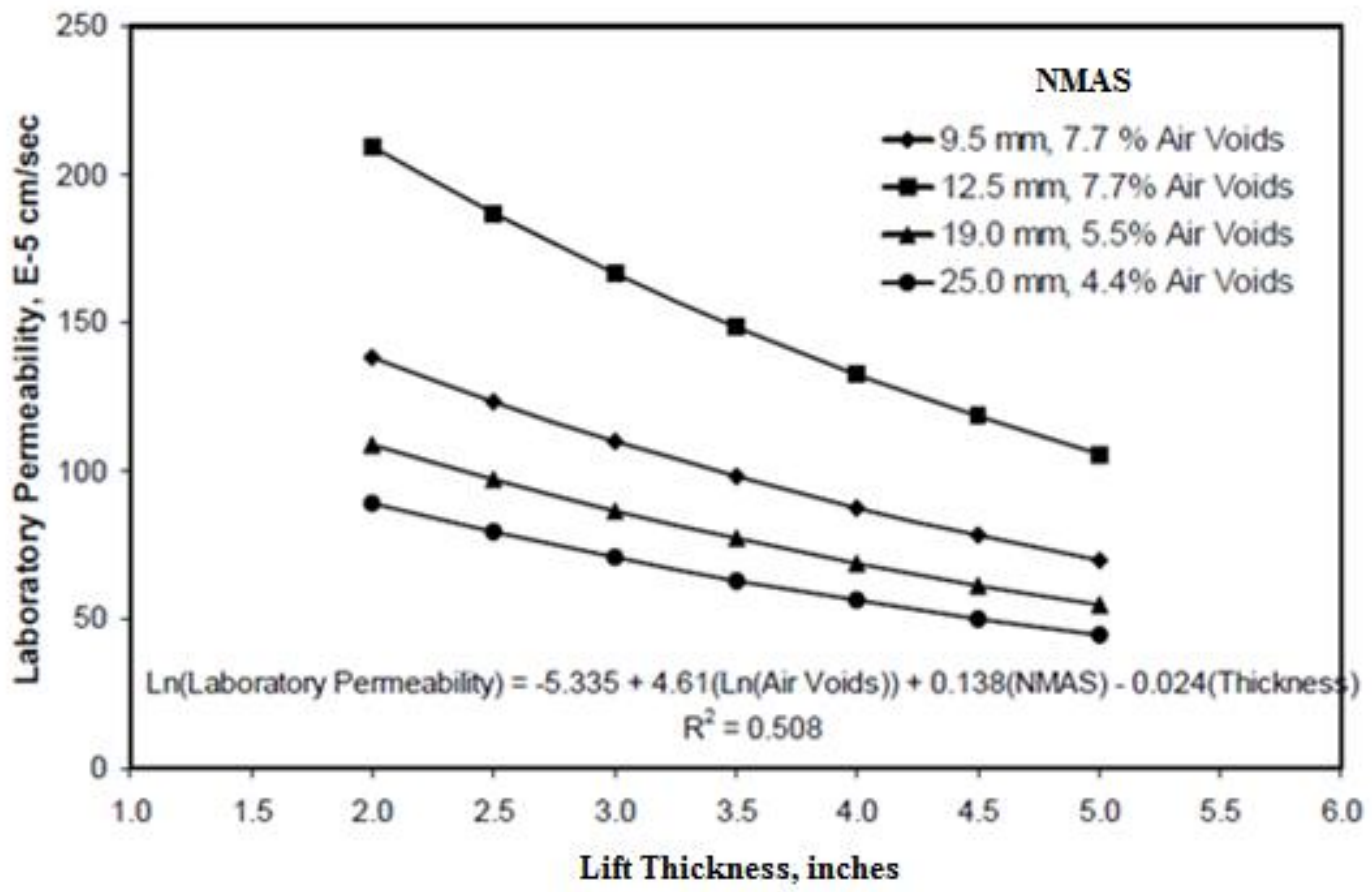

Figure 2.4: Permeability vs. Lift Thickness to NMAS

\subsubsection{Compaction}

Compaction is the process by which the volume of air in an HMAC mixture is reduced by using external forces to reorient the aggregate particles into a more closely spaced arrangement. This reduction of air volume in a mixture produces a corresponding increase in HMAC unit weight, or density (Roberts et al., 1996). Permeability is also reduced when the amount of air is reduced within asphalt pavement. NCAT confirmed a relationship between pavement density and permeability. NCAT research also showed a correlation between density and permeability for field samples and SuperPave Gyratory Compacted (SGC) samples. Comparisons were made between density and permeability for SGC samples and field cores (Cooley et al., 2002).

\subsection{CONSTANT HEAD TEST}

The constant head test is most commonly performed when testing highly permeable asphalt or sand samples. In this test, a specimen is enclosed in a rubber membrane with porous stones at both the top and bottom. Water was then used to apply pressure to the specimen. Both inlet and outlet pressure on the water is controlled as 
water flows through the specimen. A low differential pressure is desirable to make sure that turbulent flow is not present. Figure 2.5 shows a constant head test being performed on a highly permeable sand sample (Maupin, 2000).

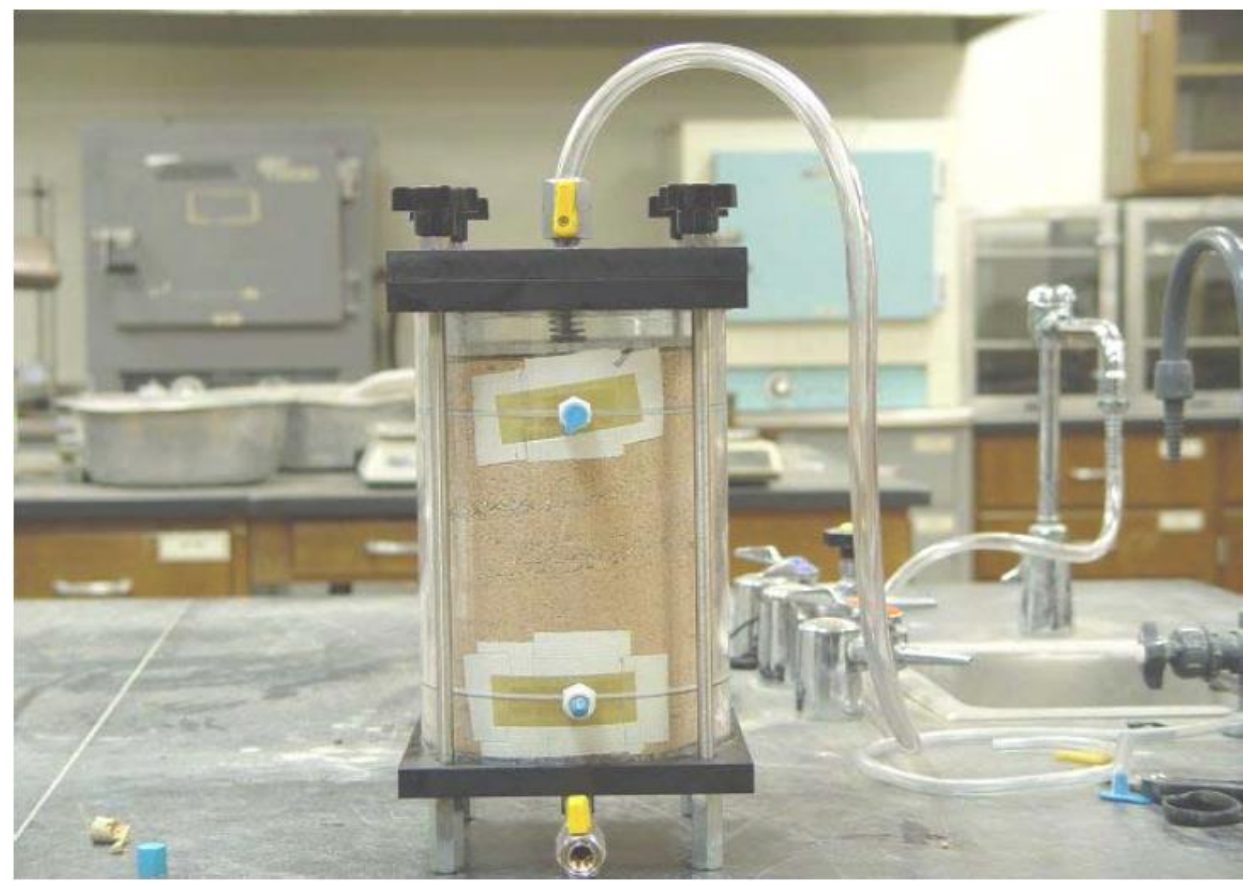

Figure 2.5: Constant Head Permeameter

The coefficient of permeability for the constant head test is calculated as:

$\mathrm{k}=\frac{Q L}{A t h}$

where:

$\mathrm{k}=$ permeability, $\mathrm{cm} / \mathrm{s}$

$\mathrm{Q}=$ quantity of flow, $\mathrm{cm}^{3}$

$\mathrm{L}=$ length of specimen, $\mathrm{cm}$

$\mathrm{A}=$ cross-sectional area of specimen, $\mathrm{cm}^{2}$

$\mathrm{t}=$ interval of time over which flow $\mathrm{Q}$ occurs, $\mathrm{s}$

$\mathrm{h}=$ difference in hydraulic head across specimen, $\mathrm{cm}$ 


\subsection{FALLING HEAD TEST}

The falling head test is the most common permeability test performed when testing low permeable asphalt concrete or clay samples. Similar to the constant head test, the falling head test evaluates the amount of head loss through a given sample over a certain period of time, shown in Figure 2.6 (Maupin, 2000).

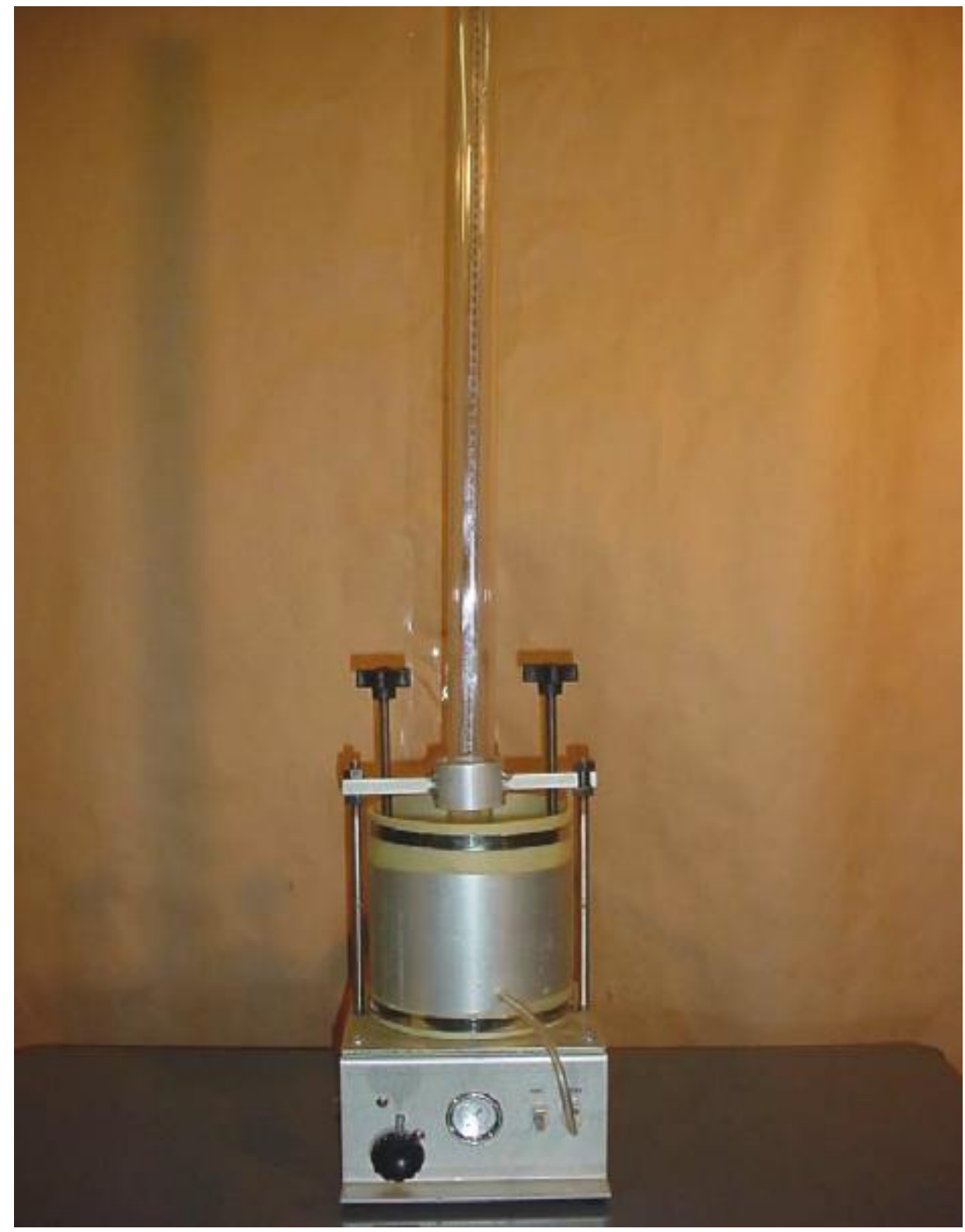

Figure 2.6: Falling Head Permeameter 
The coefficient of permeability for the falling head test is calculated as:

$$
\mathrm{k}=\frac{a L}{A t} * \ln \frac{h_{1}}{h_{2}}
$$

where:

$$
\begin{aligned}
& \mathrm{k}=\text { coefficient of permeability }, \mathrm{cm} / \mathrm{s} \\
& \mathrm{a}=\text { area of graduated cylinder, } \mathrm{cm}^{2} \\
& \mathrm{~L}=\text { length of specimen, } \mathrm{cm} \\
& \mathrm{A}=\text { cross-sectional area of specimen, } \mathrm{cm}^{2} \\
& \mathrm{t}=\text { time of flow between heads, } \mathrm{s} \\
& \mathrm{h}_{1}=\text { initial head of water, } \mathrm{cm} \\
& \mathrm{h}_{2}=\text { final head of water, } \mathrm{cm}
\end{aligned}
$$

\subsection{FLORIDA PERMEABILITY METHOD}

The Florida asphalt permeability test method is used in the laboratory for the determination of water permeability in a compacted asphalt sample. Either field or laboratory specimens can be used in this procedure. This procedure uses a falling head permeability testing apparatus, shown in Figure 2.8, which is used to determine the rate of laminar flow of water through the asphalt specimen. The testing apparatus uses a graduated cylinder that is filled with a predetermined volume of water. Water flows through a compacted asphalt specimen, while the time it takes for a specified change of head is recorded. Using Darcy's law, the coefficient of permeability can be determined. 
The Florida asphalt permeameter has many requirements in order for the apparatus to be valid, Figure 2.7:

a.) The calibrated cylinder must have an inner diameter of $31.75 \pm 0.5 \mathrm{~mm}$ and must be capable of dispensing $500 \mathrm{ml}$ of water.

b.) A flexible latex membrane must be used as a sealing tube $0.635 \mathrm{~mm}$ thick and must be able to contain asphalt specimens up to $152.4 \mathrm{~mm}$ in diameter and $80 \mathrm{~mm}$ in height.

c.) The upper cap for supporting the graduated cylinder must have an opening the same diameter as the inner diameter of the calibrated cylinder mentioned in part (a). The underside of the upper cap must be tapered at an angle of $10 \pm 1^{\circ}$.

d.) A pedestal plate must be placed under asphalt specimen and expanding an o-ring against the sealing tube. The plate must have an opening that has a minimum diameter of $18 \mathrm{~mm}$. The topside of the lower cap must also be tapered at an angle of $10 \pm 1^{\circ}$.

e.) The o-rings used must have a sufficient diameter and thickness for maintaining a seal against the sealing tube.

f.) A frame and clamp assembly must be used for supplying a compressive force to the upper cap and a lower pedestal is necessary to expand the o-rings.

g.) An air pump must be capable of applying $15 \mathrm{psi}(103.42 \mathrm{kPa})$ of pressure and must be able to apply vacuum for the evacuation of air from the sealing tube/membrane cavity.

h.) The pressure gauge used must have a range from 0 to $15 \mathrm{psi}$ ( 0 to $103.42 \mathrm{kPa})$ with $\pm 2 \%$ accuracy.

i.) Quick connects and a pressure line must be used for inflating and evacuating the sealing tube/membrane cavity.

j.) An outlet pipe must be used with a minimum inside diameter of $18 \mathrm{~mm}$ with a shutoff valve for draining water. 


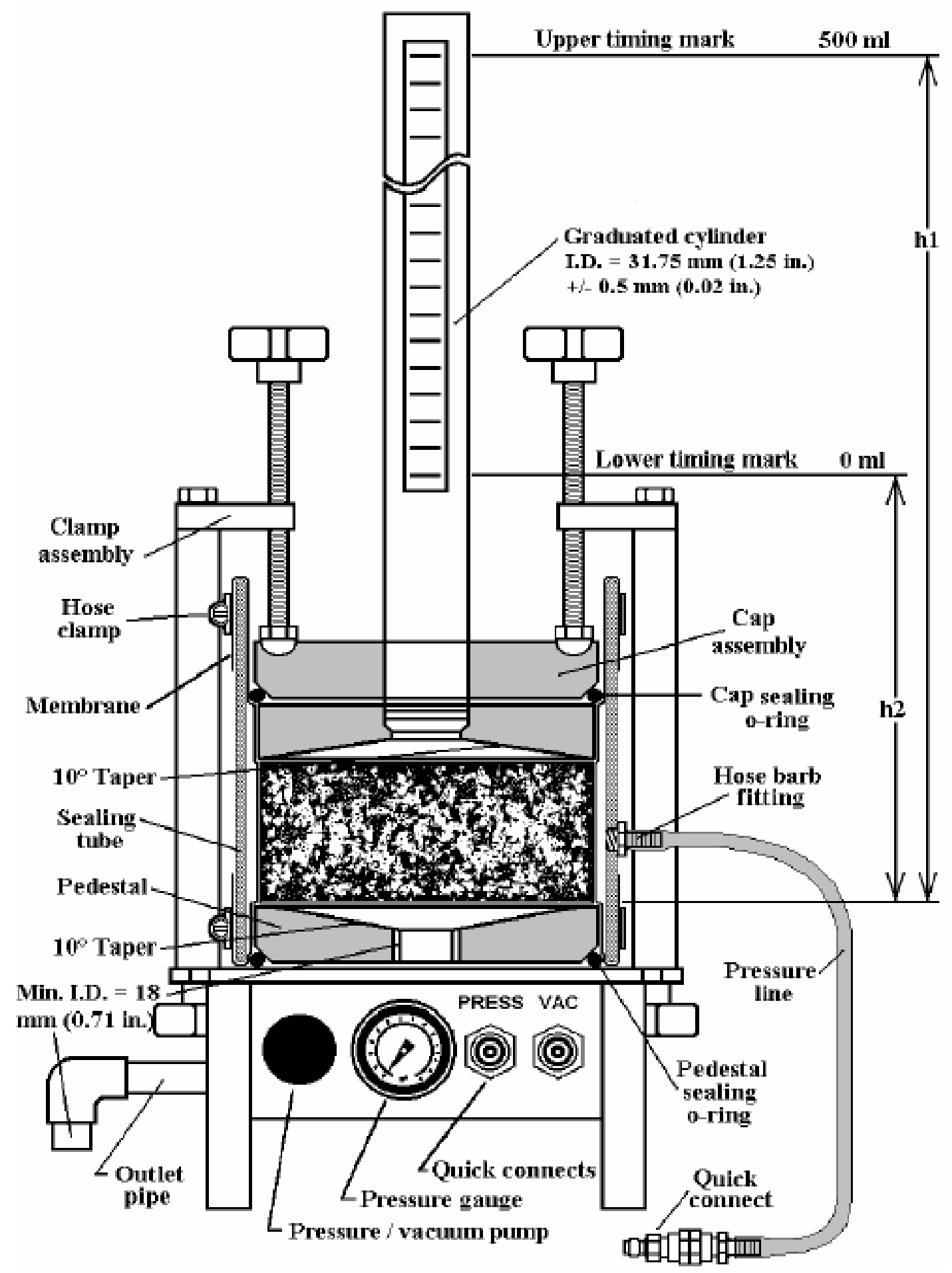

Figure 2.7: Water Permeability Testing Apparatus (Not to Scale)

(Florida Department of Transportation) 
Each asphalt specimen must be prepared in a specific manner before testing. The sample must first be compacted to a desired thickness and washed thoroughly with water to remove all loose and fine material. The bulk specific gravity of the specimen is then measured. The height and diameter of the specimen must be measured and recorded to the nearest $0.5 \mathrm{~mm}$ in three locations. The three measurements of both the height and diameter must not vary more than $5 \mathrm{~mm}$ and the diameter of the specimen must be at least $144 \mathrm{~mm}$. Using a spatula or a similar device, a thin layer of petroleum jelly is to be applied to the sides of the specimen. The jelly will fill the void areas around the sides which are not representative of the level of compaction of the interior of the specimen. The sample must be wiped with a towel to remove all water before the petroleum jelly is applied.

The air from the sealing tube/membrane cavity must be removed at the beginning of the permeability test. All air is removed by pinching the membrane while pulling it away from the hose barb fitting. The test specimen must be placed on top of the lower plate and centered. The sealing tube must be placed over the test specimen and the lower pedestal plate once the test specimen is centered. The sealing tube is placed so that the hose barb fitting is located between the o-rings on the upper cap and lower pedestal. The upper cap assembly is placed into the sealing tube and rests on the top of the specimen. To seal the specimen, two clamps are evenly tightened on the frame. After clamps are securely tightened, the membrane is inflated and maintained at $10 \pm 0.5$ psi throughout the entire test. Water is then filled above the upper timing mark. The timer is started once the bottom of the meniscus of water reaches the upper timing mark. The timer is stopped when the bottom of the meniscus reaches the bottom timing mark. This process is repeated three times until the difference between the first and third test is less than four percent. The temperature of the water in the graduated cylinder is measured to the closest $0.1{ }^{\circ} \mathrm{C}$. 
The coefficient of permeability can be calculated as:

$$
k=\frac{a L}{A t} \ln \left(h_{1} / h_{2}\right) * t_{c}
$$

where:

$\mathrm{k}=$ coefficient of permeability, $\mathrm{cm} / \mathrm{s}$

$\mathrm{a}=$ inside cross-sectional area of graduated cylinder, $\mathrm{cm}^{2}$

$\mathrm{L}=$ average thickness of test specimen, $\mathrm{cm}$

$\mathrm{A}=$ average cross-sectional area of test specimen, $\mathrm{cm}^{2}$

$\mathrm{t}=$ elapsed time between $\mathrm{h}_{1}$ and $\mathrm{h}_{2}, \mathrm{~s}$

$\mathrm{h}_{1}=$ initial head across test specimen, $\mathrm{cm}$

$\mathrm{h}_{2}=$ final head across test specimen, $\mathrm{cm}$

$t_{c}=$ temperature correction for viscosity of water (Table 2.1)

* A temperature of $20^{\circ} \mathrm{C}$ is used as the standard by the FDOT 
Table 2.1: Temperature Correction for Viscosity of Water, Celsius

\begin{tabular}{|c|c|c|c|c|c|c|c|c|c|c|}
\hline${ }^{\circ} \mathrm{C}$ & 0.0 & 0.1 & 0.2 & 0.3 & 0.4 & 0.5 & 0.6 & 0.7 & 0.8 & 0.9 \\
\hline 10 & 1.30 & 1.30 & 1.29 & 1.29 & 1.29 & 1.28 & 1.28 & 1.27 & 1.27 & 1.27 \\
\hline 11 & 1.26 & 1.26 & 1.26 & 1.25 & 1.25 & 1.25 & 1.24 & 1.24 & 1.24 & 1.23 \\
\hline 12 & 1.23 & 1.23 & 1.22 & 1.22 & 1.22 & 1.21 & 1.21 & 1.21 & 1.20 & 1.20 \\
\hline 13 & 1.20 & 1.19 & 1.19 & 1.19 & 1.18 & 1.18 & 1.18 & 1.17 & 1.17 & 1.17 \\
\hline 14 & 1.16 & 1.16 & 1.16 & 1.16 & 1.15 & 1.15 & 1.15 & 1.14 & 1.14 & 1.14 \\
\hline 15 & 1.13 & 1.13 & 1.13 & 1.13 & 1.12 & 1.12 & 1.12 & 1.11 & 1.11 & 1.11 \\
\hline 16 & 1.10 & 1.10 & 1.10 & 1.10 & 1.09 & 1.09 & 1.09 & 1.09 & 1.08 & 1.08 \\
\hline 17 & 1.08 & 1.07 & 1.07 & 1.07 & 1.07 & 1.06 & 1.06 & 1.06 & 1.06 & 1.05 \\
\hline 18 & 1.05 & 1.05 & 1.05 & 1.04 & 1.04 & 1.04 & 1.03 & 1.03 & 1.03 & 1.03 \\
\hline 19 & 1.02 & 1.02 & 1.02 & 1.02 & 1.01 & 1.01 & 1.01 & 1.01 & 1.00 & 1.00 \\
\hline 20 & 1.00 & 1.00 & 1.00 & 0.99 & 0.99 & 0.99 & 0.99 & 0.98 & 0.98 & 0.98 \\
\hline 21 & 0.98 & 0.97 & 0.97 & 0.97 & 0.97 & 0.96 & 0.96 & 0.96 & 0.96 & 0.96 \\
\hline 22 & 0.95 & 0.95 & 0.95 & 0.95 & 0.94 & 0.94 & 0.94 & 0.94 & 0.94 & 0.93 \\
\hline 23 & 0.93 & 0.93 & 0.93 & 0.93 & 0.92 & 0.92 & 0.92 & 0.92 & 0.91 & 0.91 \\
\hline 24 & 0.91 & 0.91 & 0.91 & 0.90 & 0.90 & 0.90 & 0.90 & 0.90 & 0.89 & 0.89 \\
\hline 25 & 0.89 & 0.89 & 0.89 & 0.88 & 0.88 & 0.88 & 0.88 & 0.88 & 0.87 & 0.87 \\
\hline 26 & 0.87 & 0.87 & 0.87 & 0.87 & 0.86 & 0.86 & 0.86 & 0.86 & 0.86 & 0.85 \\
\hline 27 & 0.85 & 0.85 & 0.85 & 0.85 & 0.84 & 0.84 & 0.84 & 0.84 & 0.84 & 0.84 \\
\hline 28 & 0.83 & 0.83 & 0.83 & 0.83 & 0.83 & 0.83 & 0.82 & 0.82 & 0.82 & 0.82 \\
\hline 29 & 0.82 & 0.81 & 0.81 & 0.81 & 0.81 & 0.81 & 0.81 & 0.80 & 0.80 & 0.80 \\
\hline 30 & 0.80 & 0.80 & 0.80 & 0.79 & 0.79 & 0.79 & 0.79 & 0.79 & 0.79 & 0.78 \\
\hline 31 & 0.78 & 0.78 & 0.78 & 0.78 & 0.78 & 0.78 & 0.77 & 0.77 & 0.77 & 0.77 \\
\hline 32 & 0.77 & 0.77 & 0.76 & 0.76 & 0.76 & 0.76 & 0.76 & 0.76 & 0.76 & 0.75 \\
\hline 33 & 0.75 & 0.75 & 0.75 & 0.75 & 0.75 & 0.74 & 0.74 & 0.74 & 0.74 & 0.74 \\
\hline 34 & 0.74 & 0.74 & 0.73 & 0.73 & 0.73 & 0.73 & 0.73 & 0.73 & 0.73 & 0.72 \\
\hline 35 & 0.72 & 0.72 & 0.72 & 0.72 & 0.72 & 0.72 & 0.71 & 0.71 & 0.71 & 0.71 \\
\hline & & & & & & & & & & \\
\hline
\end{tabular}




\subsection{INDIRECT TENSION TEST}

The indirect tension (IDT) strength test is used to evaluate the rut resistance of hot mix asphalt concrete (HMAC) mixtures. Since the implementation of the SuperPave mix design process, engineers have expressed concern over the lack of a test to ensure that mixtures have adequate stability and rut resistance. The IDT test method is simple, quick, and can be run using a standard Marshall stabilometer equipped with an IDT loading head. Most construction materials laboratories can run this test without any additional expenses on equipment and training. This test also appears to correlate well to HMAC rut resistance for a wide range of mixtures (Christensen et al., 2007).

\subsubsection{IDT Test procedure}

The testing machine used to load the asphalt specimens should have a minimum capacity of 5,000 lbf and should be capable of applying a load at a rate of $0.17 \mathrm{ft} / \mathrm{min}$. The testing system should include a means of measuring the failure load to an accuracy of \pm 10 lbf. Asphalt specimens should be prepared using a SuperPave gyratory compactor to a height of $115 \pm 10 \mathrm{~mm}$ and $150 \mathrm{~mm}$ in diameter. The test temperature should be $9^{\circ} \mathrm{C}$ lower than the yearly 7 -day average. Specimens should be conditioned prior to testing for 1 to 2 hours in a controlled temperature chamber or for 30 to 60 minutes in a controlled temperature water bath. If a water bath is used for conditioning, specimens should be tightly sealed in a plastic bag prior to immersion. After conditioning, specimens should then be placed in the testing apparatus and immediately loaded to failure at $50 \mathrm{~mm} / \mathrm{min}$. Specimen should be placed in testing apparatus within 60 seconds of removal from chamber or water bath. 
IDT strength is calculated as:

$$
\sigma_{I D T}=\frac{2 P}{\Pi t D}
$$

where:

$$
\begin{aligned}
& \sigma_{I D T}=\text { IDT strength, } \mathrm{Pa} \\
& \mathrm{P}=\text { maximum applied load, } \mathrm{N} \\
& \pi=3.1416 \\
& \mathrm{t}=\text { thickness, } \mathrm{m} \\
& \mathrm{D}=\text { diameter, } \mathrm{m}
\end{aligned}
$$

Two asphalt samples should be tested, and the average of the two strengths recorded as the IDT strength. The rut resistance of a mixture based upon the results of the high-temperature IDT strength test is computed as (Christensen et al., 2007):

$$
\begin{aligned}
\mathrm{TR}_{\max } & =1.97 \times 10^{-5}(\mathrm{IDT})^{2.549} \\
& \text { where: } \\
& \mathrm{TR}_{\max }=\text { maximum allowable traffic for given mixture, millions ESALs } \\
& \text { IDT }=\text { high-temperature IDT strength, } \mathrm{kPa}
\end{aligned}
$$

\subsection{CASE STUDIES}

\subsubsection{Pennsylvania}

A case study performed in Pennsylvania in 2001 documents the effect of pavement saturation. The authors suggest that under completely saturated conditions, all asphalt mixes may fail due to repeated hydraulic stress which physically separates the aggregate from the asphalt binder.

The case history presented in this study by Auburn University give the details of construction, visual observation of pavement distress, sampling and testing of pavement, and conclusions/recommendations. A jackhammer was used for dry sampling to 
determine a moisture profile within the pavement structure. The phenomenon of stripping was investigated, looking at the relative permeability of the pavement components, subsurface drainage system, and the interaction between different asphalt courses including open-graded friction courses. Various hypotheses are presented throughout the paper to explain the mechanisms that resulted in the observed pavement saturation and recommendations were made to reduce instances of premature failures caused by stripping.

The case study was done on the Pennsylvania turnpike in Cumberland County between mile posts 209.5 and 218.0. In 1994 this section of the turnpike received an asphalt overlay consisting of a $37 \mathrm{~mm}$ thick ID-2 wearing course (dense graded $9.5 \mathrm{~mm}$ NMAS mix). The percentage of material passing the $4.75 \mathrm{~mm}, 2.36 \mathrm{~mm}$, and $0.075 \mathrm{~mm}$ sieves were $71 \%, 45 \%$, and $4.5 \%$ respectively, with a design binder content of $6.3 \%$. The overlay was placed between April and November 1994 and the aggregate was 100\% crushed stone. The existing road was milled to an average depth of $40 \mathrm{~mm}$ prior to the overlay.

Approximately two years later, in 1996, the project started to show signs of premature distress in the westbound slow lane between mile posts 215.5 and 218.0. Signs included fines brought up to the surface by water, flushing of the surface, and potholing. Potholes were visible in the wheel tracks on the west bound slow lane; more were found on the inside tracks than the outside tracks. There were no signs of significant distress between mile posts 209.5 and 215.5. A jackhammer was used to cut samples at various locations of the pavement in both the distressed and good areas. Three $500 \mathrm{~mm} \times 500 \mathrm{~mm}$ samples were taken on mile post 217.65 on the inside wheel track, between the wheel tracks, and on the outside wheel track. Each sample that was taken was examined for moisture content and maximum theoretical gravity.

In addition, three $150 \mathrm{~mm}$ diameter cores were taken adjacent to the samples mentioned above to determine the thickness, bulk specific gravity, and air void content of each pavement layer. Similar samples were also taken in the good area at mile post 212.9. Table 2.2 and Table 2.3 give a brief summary of the observations for each 
pavement layer at the three sample locations at mile posts 217.65 and 212.90 in the westbound slow lane (Kandhal et al., 2001).

Table 2.2: Visual Observations of Holes at MP 217.65 in Westbound Slow Lane

\begin{tabular}{|c|c|c|c|}
\hline Pavement Layer & Inside Wheel Track (IWT) & $\begin{array}{l}\text { Between Wheel Tracks } \\
\text { (BWT) }\end{array}$ & $\begin{array}{l}\text { Outside Wheel } \\
\text { Track (OWT) }\end{array}$ \\
\hline $\begin{array}{l}\text { New Gravel } \\
\text { Wearing Course }\end{array}$ & $\begin{array}{l}\text { Moist, stripping at the bottom } \\
(50 \%) \text {, excess asphalt binder can } \\
\text { be seen migrating toward the } \\
\text { surface }\end{array}$ & $\begin{array}{l}\text { Observations similar to } \\
\text { IWT except mix was } \\
\text { moist to wet and } \\
\text { stripping was about } 40 \%\end{array}$ & $\begin{array}{l}\text { Observation } \\
\text { similar to IWT }\end{array}$ \\
\hline $\begin{array}{l}\text { Old Limestone } \\
\text { Binder Course }\end{array}$ & $\begin{array}{l}\text { Very wet, badly stripped ( } 80 \%) \text {, } \\
\text { bare aggregate particles give an } \\
\text { appearance of a French drain }\end{array}$ & $\begin{array}{l}\text { Observations similar to } \\
\text { IWT }\end{array}$ & $\begin{array}{l}\text { Observation } \\
\text { similar to IWT }\end{array}$ \\
\hline $\begin{array}{l}\text { Old Gravel } \\
\text { Wearing Course }\end{array}$ & $\begin{array}{l}\text { Moist to wet, stripped ( } 50 \%) \text {, } \\
\text { mix is very friable, can be } \\
\text { broken with hand }\end{array}$ & $\begin{array}{l}\text { Observations similar to } \\
\text { IWT }\end{array}$ & $\begin{array}{l}\text { Observation } \\
\text { similar to IWT }\end{array}$ \\
\hline $\begin{array}{l}\text { Old Slag } \\
\text { Wearing Course }\end{array}$ & Moist, minimal stripping & $\begin{array}{l}\text { Observations similar to } \\
\text { IWT }\end{array}$ & $\begin{array}{l}\text { Observation } \\
\text { similar to IWT }\end{array}$ \\
\hline $\begin{array}{l}\text { Old Limestone } \\
\text { Binder Course }\end{array}$ & Wet, partly stripped & $\begin{array}{l}\text { Observations similar to } \\
\text { IWT }\end{array}$ & $\begin{array}{l}\text { Observation } \\
\text { similar to IWT }\end{array}$ \\
\hline Concrete & Wet & $\begin{array}{l}\text { Observations similar to } \\
\text { IWT }\end{array}$ & $\begin{array}{l}\text { Observation } \\
\text { similar to IWT }\end{array}$ \\
\hline
\end{tabular}

Table 2.3: Visual Observations of Holes at MP 212.90 in Westbound Slow Lane

\begin{tabular}{|c|c|c|c|}
\hline Pavement Layer & Inside Wheel Track (IWT) & $\begin{array}{l}\text { Between Wheel Tracks } \\
\text { (BWT) }\end{array}$ & $\begin{array}{l}\text { Outside Wheel } \\
\text { Track (OWT) }\end{array}$ \\
\hline $\begin{array}{l}\text { New Gravel } \\
\text { Wearing Course }\end{array}$ & $\begin{array}{l}\text { Moist, stripping at the bottom } \\
(40 \%) \text {, excess asphalt binder } \\
\text { can be seen migrating toward } \\
\text { the surface }\end{array}$ & $\begin{array}{l}\text { Observations similar to } \\
\text { IWT }\end{array}$ & $\begin{array}{l}\text { Observation similar } \\
\text { to IWT }\end{array}$ \\
\hline $\begin{array}{l}\text { Old Limestone } \\
\text { Binder Course }\end{array}$ & $\begin{array}{l}\text { Wet, badly stripped ( } 80 \%) \text {, } \\
\text { loss of cavities }\end{array}$ & $\begin{array}{l}\text { Observations similar to } \\
\text { IWT except stripping is } \\
\text { about } 70 \%\end{array}$ & $\begin{array}{l}\text { Observation similar } \\
\text { to IWT }\end{array}$ \\
\hline $\begin{array}{l}\text { Old Gravel } \\
\text { Wearing Course }\end{array}$ & $\begin{array}{l}\text { Moist to wet, stripped ( } 50 \%) \text {, } \\
\text { mix is very friable, can be } \\
\text { broken with hand }\end{array}$ & $\begin{array}{l}\text { Observations similar to } \\
\text { IWT except the mix is } \\
\text { moist }\end{array}$ & $\begin{array}{l}\text { Observation similar } \\
\text { to IWT }\end{array}$ \\
\hline $\begin{array}{l}\text { Old Slag } \\
\text { Wearing Course }\end{array}$ & Moist, minimal stripping & $\begin{array}{l}\text { Observations similar to } \\
\text { IWT except the mix is } \\
\text { moist }\end{array}$ & $\begin{array}{l}\text { Observation similar } \\
\text { to IWT }\end{array}$ \\
\hline $\begin{array}{l}\text { Old Limestone } \\
\text { Binder Course }\end{array}$ & Wet, partly stripped & $\begin{array}{l}\text { Observations similar to } \\
\text { IWT except the mix is } \\
\text { moist }\end{array}$ & $\begin{array}{l}\text { Observation similar } \\
\text { to IWT }\end{array}$ \\
\hline Concrete & Wet & $\begin{array}{l}\text { Observations similar to } \\
\text { IWT except the mix is } \\
\text { moist }\end{array}$ & $\begin{array}{l}\text { Observation similar } \\
\text { to IWT }\end{array}$ \\
\hline
\end{tabular}


In addition to visual observations, bulk specific gravity, maximum theoretical specific gravity, percent air voids, percent moisture by weight, and percent saturation were calculated in each of the three sample locations. Table 2.4 and Table 2.5 give these values at both mile posts at three different pavement layers.

Table 2.4: Density, Moisture, and Saturation Data, MP 217.65 Westbound Slow Lane

\begin{tabular}{llccc}
\hline \multirow{2}{*}{ Layer } & \multicolumn{1}{c}{ Property } & \multicolumn{2}{c}{ Location } \\
\cline { 3 - 5 } & & $\begin{array}{c}\text { Inside Wheel } \\
\text { Track (1) }\end{array}$ & $\begin{array}{c}\text { Between Wheel } \\
\text { Tracks (2) }\end{array}$ & $\begin{array}{c}\text { Outside Wheel } \\
\text { Track (3) }\end{array}$ \\
\hline A. New Gravel & Bulk Sp. Gr. & 2.362 & 2.304 & 2.376 \\
Wearing Course & \% Air Voids* & 2.1 & 4.5 & 1.5 \\
& \% Moisture by wt. & 1.2 & 2.6 & 0.7 \\
& \% Saturation & 135 & 133 & 110 \\
\hline B. Old Limestone & Bulk Sp. Gr. & 2.416 & 2.419 & 2.442 \\
Binder Course & \% Air Voids** & 3.3 & 3.2 & 0.9 \\
& \% Moisture by wt. & 1.1 & 1.3 & 96 \\
\hline C. Old Gravel & Bulk Sp. Gr. & 80 & 98 & 2.240 \\
Wearing Course & \% Air Voids*** & 2.223 & 2.220 & 4.2 \\
& \% Moisture by wt. & 4.9 & 5.0 & 3.0 \\
& \% Saturation & 3.2 & 3.3 & 160 \\
\hline * Based
\end{tabular}

* Based on an average maximum theoretical specific gravity of 2.413

$* *$ Based on an average maximum theoretical specific gravity of 2.499

**** Based on an average maximum theoretical specific gravity of 2.337

Table 2.5: Density, Moisture, and Saturation Data, MP 212.90 Westbound Slow Lane

\begin{tabular}{llccc}
\hline \multirow{2}{*}{ Layer } & \multicolumn{1}{c}{ Property } & \multicolumn{2}{c}{ Location } \\
\cline { 3 - 5 } & & $\begin{array}{c}\text { Inside Wheel } \\
\text { Track (1) }\end{array}$ & $\begin{array}{c}\text { Between Wheel } \\
\text { Tracks (2) }\end{array}$ & $\begin{array}{c}\text { Outside Wheel } \\
\text { Track (3) }\end{array}$ \\
\hline A. New Gravel & Bulk Sp. Gr. & 2.349 & 2.252 & 2.361 \\
Wearing Course & \% Air Voids* & 2.7 & 6.7 & 2.2 \\
& \% Moisture by wt. & 1.3 & 1.7 & 1.3 \\
& \% Saturation & 113 & 57 & 140 \\
\hline B. Old Limestone & Bulk Sp. Gr. & 2.453 & 2.437 & 2.471 \\
Binder Course & \% Air Voids* & 1.8 & 2.5 & 0.9 \\
& \% Moisture by wt. & 1.0 & 1.1 & 202 \\
\hline C. Old Gravel & Bulk Sp. Gr. & 136 & 2.212 & 2.240 \\
Wearing Course & \% Air Voids*** & 2.266 & 5.4 & 4.2 \\
& \% Moisture by wt. & 3.0 & 2.9 & 2.6 \\
& \% Saturation & 3.2 & 119 & 139 \\
\hline
\end{tabular}

* Based on an average maximum theoretical specific gravity of 2.413

*** Based on an average maximum theoretical specific gravity of 2.499

**** Based on an average maximum theoretical specific gravity of 2.337

The results of this field experiment concluded that pore pressure due to repeated heavy traffic caused the stripping of asphalt binder from the aggregate. The new wearing 
course with gravel aggregates was almost impermeable to surface water because the in-situ air void content was generally lower than 5 percent. Due to inadequate subsurface drainage, the new wearing course was being stripped from the bottom upwards by water coming from underneath the pavement. Although pavement distress has not began on the surface between mile posts 209.5 and 215.5 , stripping has already started on the underlying layers beneath the new gravel wearing course. Signs of pavement distress on the surface are expected to begin in the near future just as seen between mile posts 215.5 and 218.0. The delay in the distress between mile posts 209.5 and 215.5 was not explained, but it is thought to be the difference in the construction of the subsurface draining conditions (Kandhal et al., 2001).

\subsubsection{Louisiana}

The Louisiana Transportation Research Center (LTRC) performed laboratory permeability tests on field cores taken from seventeen SuperPave projects within Louisiana. Similar to the Florida Test Method, the LTRC used a modified version of the Karol-Warner's falling head permeameter. In addition, volumetric properties that affect permeability such as air void content, compaction effort, mixture gradation, and lift thickness were related using a sensitivity analysis. A regression model was developed to be able to predict the permeability from the volumetric properties. The primary goal of this research was to evaluate the permeability of SuperPave mixtures used in Louisiana, study the effects of volumetric properties of the mix on permeability, and to estimate the coefficient of permeability using a prediction model (Mohammad et al., 2003).

A total of twenty-four $19 \mathrm{~mm}$ and $25 \mathrm{~mm}$ wearing and binder course mixtures were evaluated from the Louisiana 1998 and 1999 SuperPave implementation projects. Three levels of design traffic were used. The traffic level determines the compaction effort used to select the design binder content. In general, a higher compaction effort is used as the traffic level increases, which results in lower design binder content. Below is a breakdown of the mixtures evaluated: 
1998 SuperPave Projects

\section{Layer}

(7) wearing course mixtures

(6) binder course mixtures
NMAS

(8) 19mm mixtures (7) Level 1 ( $<3$ mill. ESALs)

(5) $25 \mathrm{~mm}$ mixtures (3) Level 2 (3-30 mill. ESALs)

(3) Level 3 (>30 mill. ESALs)

1999 SuperPave Projects

(8) wearing course mixtures

(3) binder course mixtures
(8) $19 \mathrm{~mm}$ mixtures (3) Level 1 ( $<3$ mill. ESALs)

(3) 25mm mixtures (2) Level 2 (3-30 mill. ESALs)

(6) Level 3 (>30 mill. ESALs)

The $150 \mathrm{~mm}$ diameter core samples were collected in accordance with ASTM D979 "Standard Practice for Sampling Bituminous Paving Mixtures" and were separated by layers. The permeameter used in this study has the capability to perform both falling head and constant head tests, although only the falling head test was used. Similar to the Florida method, Darcy's Law was used to calculate the coefficient of permeability from equation 2.2 (No temperature correction).

Many variables were considered when calculating permeability of an asphalt mix: specimen thickness, percent of air voids, gradation of the mix (coarse vs. fine), asphalt content, and compaction. This study conducted experiments to evaluate the effect of each of these variables when determining asphalt permeability.

Asphalt mixtures were considered permeable when the coefficient of permeability values was greater than $125 \times 10^{-4} \mathrm{~mm} / \mathrm{s}$. An air void content of approximately $5.3 \%$ and above is where the asphalt mixtures began to become permeable. The effect of mixture gradation was another important variable considered. The mixtures were classified as fine or coarse graded based on the gradation being above or below the maximum density line respectively.

The permeability values of the coarse-graded mixture were above $125 \times 10^{-4} \mathrm{~mm} / \mathrm{s}$ when the air void content exceeded 5.3\%, while all fine-graded mixtures in this study 
were found to be impermeable at all air void levels. Thus, coarser blends were found to be more permeable then finer blends. Even though the aggregate gradation and air void levels may be similar, they may have different coefficient of permeability values due to the various arrangement of aggregates inside the mixture.

The last variable that was tested was compaction. It was concluded that there was no overall difference of permeability between the three traffic levels, although some mixtures at level 2 showed higher permeability values. A statistical regression model was developed using a statistical analysis system (SAS) to predict the permeability. The variables mentioned above were factors considered when developing this model. Three data sets of mixtures were considered in the development of the prediction model: phase I wearing course, phase I binder course, and phase II binder course mixtures. The permeability prediction model was found to be:

$$
K=10^{-4}\left\{\begin{array}{l}
76.6(\% \text { Airvoids })-17.2 P_{0.075}+163.4 P_{0.3}-197.5 P_{0.6} \\
+33.2 P_{2.36}+4.5 P_{12.5}-1.7 L
\end{array}\right\}
$$

where,

$$
\begin{aligned}
& K=\text { coefficient of permeability }(\mathrm{mm} / \mathrm{s}) \text {, } \\
& P_{0.075}=\text { percent passing sieve } 0.075 \mathrm{~mm} \text {, } \\
& P_{0.3}=\text { percent passing sieve } 0.3 \mathrm{~mm} \text {, } \\
& P_{0.6}=\text { percent passing sieve } 0.6 \mathrm{~mm} \text {, } \\
& P_{2.36}=\text { percent passing sieve } 2.36 \mathrm{~mm} \text {, } \\
& P_{12.5}=\text { percent passing sieve } 12.5 \mathrm{~mm} \text {, and } \\
& \mathrm{L} \quad=\text { height of the specimen (mm) }
\end{aligned}
$$


Table 2.6: Selection of Model Parameters

\begin{tabular}{|l|l|c|}
\hline \multicolumn{1}{|c|}{ Model parameters } & \multicolumn{1}{|c|}{ Condition } & $\mathrm{R}^{2}$ \\
\hline $\begin{array}{l}\mathrm{K}, \% \text { air void, } \mathrm{p}_{0.075}, \mathrm{p}_{0.3}, \\
\mathrm{p}_{0.6}, \mathrm{p}_{2.36}, \mathrm{p}_{12.5}, \mathrm{~L}\end{array}$ & With all parameters & 0.9439 \\
\hline $\begin{array}{l}\mathrm{K}, \% \text { air void, } \mathrm{p}_{0.075}, \mathrm{p}_{0.3}, \\
\mathrm{p}_{0.6}, \mathrm{p}_{2.36}, \mathrm{p}_{12.5}\end{array}$ & Without thickness, $\mathrm{L}$ & 0.9417 \\
\hline $\begin{array}{l}\mathrm{K}, \% \text { air void, } \mathrm{p}_{0.075}, \mathrm{p}_{0.3}, \\
\mathrm{p}_{0.6}, \mathrm{p}_{2.36}, \mathrm{~L}\end{array}$ & Without $\mathrm{p}_{12.5}$ & 0.9399 \\
\hline $\begin{array}{l}\mathrm{K}, \% \text { air void, } \mathrm{p}_{0.075}, \mathrm{p}_{0.3}, \\
\mathrm{p}_{0.6}, \mathrm{p}_{12.5}, \mathrm{~L}\end{array}$ & Without $\mathrm{p}_{2.36}$ & 0.9403 \\
\hline $\begin{array}{l}\mathrm{K}, \% \text { air void, } \mathrm{p}_{0.075}, \mathrm{p}_{0.3}, \\
\mathrm{p}_{2.36}, \mathrm{p}_{12.5}, \mathrm{~L}\end{array}$ & Without $\mathrm{p}_{0.6}$ & 0.8373 \\
\hline $\begin{array}{l}\mathrm{K}, \% \text { air void, } \mathrm{p}_{0.075}, \mathrm{p}_{0.6}, \\
\mathrm{p}_{2.36}, \mathrm{p}_{12.5}, \mathrm{~L}\end{array}$ & Without $\mathrm{p}_{0.3}$ & 0.9437 \\
\hline $\begin{array}{l}\mathrm{K}, \% \text { air void, } \mathrm{p}_{0.3}, \mathrm{p}_{0.6}, \mathrm{p}_{2.36}, \\
\mathrm{p}_{12.5}, \mathrm{~L}\end{array}$ & Without $\mathrm{p}_{0.075}$ & 0.9353 \\
\hline $\begin{array}{l}\mathrm{K}, \mathrm{p}_{0.075}, \mathrm{p}_{0.3}, \mathrm{p}_{0.6}, \mathrm{p}_{2.36}, \\
\mathrm{p}_{12.5}, \mathrm{~L}\end{array}$ & Without air voids & 0.9373 \\
\hline
\end{tabular}

The model coefficient for the air void content was positive. This indicates, as expected, that as the air void content increases the coefficient of permeability increases. Also, as the percentage of fine aggregates passing through the $0.075 \mathrm{~mm}$ sieve increases the coefficient of permeability decreases. This occurs as a result of larger voids in the mixture are partially closed and smaller voids are created by the fine aggregates. It was also noted that the model suggests that as the thickness of the specimen increases the coefficient of permeability of asphalt mixtures decreases. This is consistent with the measured values.

The statistical model proved to be accurate and precise. All measured values calculated throughout the experiment were in agreement with the predicted values when finding the coefficient of permeability in an asphalt mix (Mohammad et al., 2003).

\subsubsection{Kansas}

The Kansas Department of Transportation conducted a study to determine the correlation between laboratory and field permeability values. In this study, laboratory and field permeability tests were performed on different SuperPave mixes with $19 \mathrm{~mm}$ and $12.5 \mathrm{~mm}$ NMAS with both coarse and fine gradations. The objective of this study was to assess whether the field permeability values could be estimated during the mixture 
design process so the mixture design could be adjusted depending upon the exact permeability desired. The Kansas DOT found that there was a significant difference between the laboratory and field permeability values. The field permeability values were consistently higher than the lab permeability values. Figure 2.8 shows the comparison of the field and laboratory permeability values at 7\% VTM (Gogula et al., 2004).

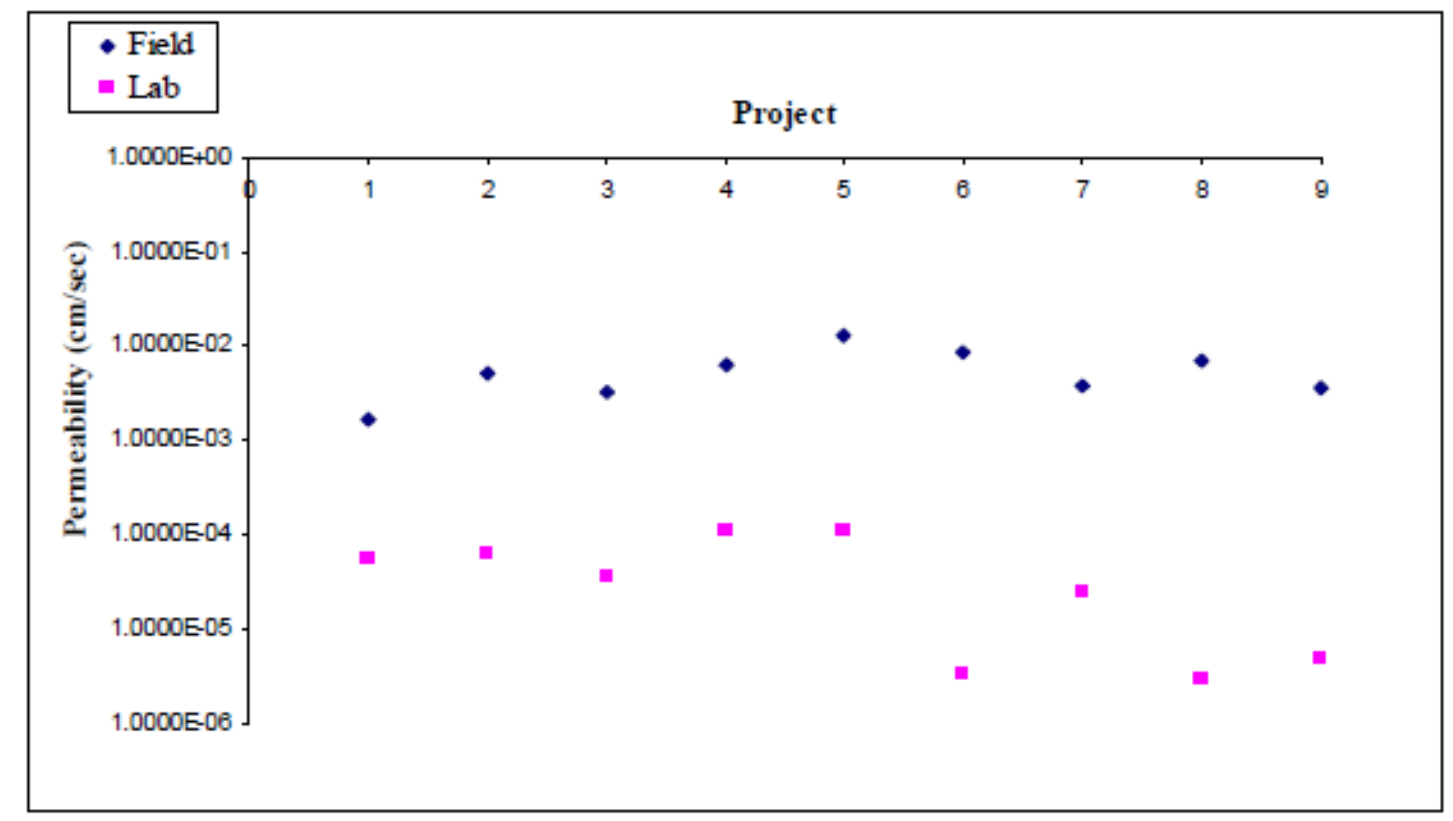

Figure 2.8: Field and Laboratory Permeability Values at 7\% VTM

\subsection{SUMMARY OF LITERATURE}

Porosity and permeability are two of the main factors that control the movement and storage of water in hot mix asphalt concrete (HMAC). A low permeable wearing surface must be placed in order to prevent pavement distress such as cracking and raveling. Additionally, the wearing surface must contain sufficient air voids to prevent rutting and shoving.

Many factors have been proven to affect permeability of HMAC. These factors include: percent air voids, nominal maximum aggregate size (NMAS), lift thickness, compaction effort, and aggregate gradation. The most important factor to consider is the percent of air voids in a mixture. Case studies have shown that an air void content 
exceeding 7-8 percent results in a drastic increase in permeability for a $9.5 \mathrm{~mm}$ wearing surface.

The most common method for testing low permeable specimens is the falling head test method. This test evaluates the amount of head loss through a given specimen over a certain period of time. The Florida permeability test method is a common falling head test and is used in the laboratory to test either field or laboratory samples. There are currently no established field test methods to determine the permeability of HMAC.

Indirect tension (IDT) strength testing is used to evaluate the rut resistance of hot mix asphalt concrete (HMAC) mixtures. The newly developed procedure can be run using a standard Marshall press so that most construction material laboratories can run this test without any additional expenses. The IDT strength and estimated maximum allowable traffic can be calculated when the recommended procedure is followed. 


\section{CHAPTER 3: RESEARCH METHODOLOGY}

\subsection{INTRODUCTION}

The emphasis of this research project was to observe how binder content affects permeability of hot mix asphalt concrete (HMAC). Asphalt samples were compacted in a gyratory compactor to $4,6,8$, and 10 percent air voids. Binder content was varied at 5.2, 5.7, 6.2, and 6.7 percent for each air void level. Throughout the research, the amount of gyrations needed to compact each sample was recorded. This was done to observe how binder content affected the compaction effort. The Florida Method of Test for Measurement of Water Permeability of Compacted Asphalt Paving Mixtures was used in this research to analyze the permeability of each asphalt sample. The indirect tension (IDT) test was then performed to evaluate the rutting resistance of each sample.

\subsection{SAMPLE PREPARATION}

Aggregate and the gradation used in this research were obtained from Greer Industries in Morgantown, West Virginia. The HMAC type was a $9.5 \mathrm{~mm}$ skid surface and was designed for 3 to 30 million ESALs. The binder used was PG 70-22. Three aggregate types were used in this research: Bluestone \#8, Bluestone Sand, and West Virginia Sand. The mixture composition consisted of 45\% Bluestone \#8, 40\% Bluestone Sand, and 15\% West Virginia Sand. Stockpile and mix gradations are given in Table 3.1 and Figure 3.1. The gradation is classified as a coarse blend. The job mix formula values were verified in the laboratory and are shown in Table 3.2. 
Table 3.1: Mixture Composition (Gradation)

\begin{tabular}{|c|c|c|c|c|c|c|c|c|}
\hline \multirow[b]{2}{*}{ Sieve Size } & \multicolumn{2}{|c|}{$\begin{array}{l}\text { Bin \#: } 1 \\
\text { Size: Bluestone \#8 } \\
\text { \% Used: } 45 \%\end{array}$} & \multicolumn{2}{|c|}{$\begin{array}{l}\text { Bin \#: } 2 \\
\text { Size: Bluestone Sand } \\
\% \text { Used: } 40 \% \\
\end{array}$} & \multicolumn{2}{|c|}{$\begin{array}{l}\text { Bin \#: } 3 \\
\text { Size: WV Sand } \\
\% \text { Used: } 15 \% \\
\end{array}$} & \multirow[b]{2}{*}{ Comb. Gradation } & \multirow[b]{2}{*}{ Master Range } \\
\hline & Passing & Total & Passing & $\%$ of Total & Passing & Total & & \\
\hline $2^{\prime \prime}(50 \mathrm{~mm})$ & 100.0 & 45.0 & 100.0 & 40.0 & 100.0 & 15.0 & 100.0 & - \\
\hline $1.5^{\prime \prime}(37.5 \mathrm{~mm})$ & 100.0 & 45.0 & 100.0 & 40.0 & 100.0 & 15.0 & 100.0 & - \\
\hline 1" (25 mm) & 100.0 & 45.0 & 100.0 & 40.0 & 100.0 & 15.0 & 100.0 & - \\
\hline $3 / 4^{\prime \prime}(19 \mathrm{~mm})$ & 100.0 & 45.0 & 100.0 & 40.0 & 100.0 & 15.0 & 100.0 & - \\
\hline $1 / 2^{\prime \prime}(12.5 \mathrm{~mm})$ & 100.0 & 45.0 & 100.0 & 40.0 & 100.0 & 15.0 & 100.0 & 100 \\
\hline $3 / 8^{\prime \prime}(9.5 \mathrm{~mm})$ & 91.0 & 41.0 & 100.0 & 40.0 & 100.0 & 15.0 & 96.0 & $90-100$ \\
\hline$\# 4$ (4.75 mm) & 20.0 & 9.0 & 99.0 & 39.6 & 90.0 & 13.5 & 62.1 & 90 Max. \\
\hline$\# 8(2.36 \mathrm{~mm})$ & 5.0 & 2.3 & 68.0 & 27.2 & 52.0 & 7.8 & 37.3 & $32-67$ \\
\hline$\# 16$ (1.18 mm) & 2.0 & 0.9 & 44.0 & 17.6 & 29.0 & 4.4 & 22.9 & - \\
\hline$\# 30(600 \mu \mathrm{m})$ & 2.0 & 0.9 & 27.0 & 10.8 & 19.0 & 2.9 & 14.6 & - \\
\hline$\# 50(300 \mu \mathrm{m})$ & 2.0 & 0.9 & 17.0 & 6.8 & 16.0 & 2.4 & 10.1 & - \\
\hline 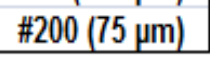 & 1.4 & 0.6 & 6.6 & 2.6 & 8.4 & 1.3 & 4.5 & $2-10$ \\
\hline
\end{tabular}

Table 3.2: Job Mix Formula Values

\begin{tabular}{|c|c|c|c|}
\hline Design Property & Accepted Target & Minimum & Maximum \\
\hline Asphalt (\%) & 5.7 & 5.4 & 6.2 \\
\hline Air Voids (\%) & 4 & 2.8 & 5.2 \\
\hline VMA (\%) & 15.8 & 14.8 & 16.8 \\
\hline VFA (\%) & 74.3 & 73 & 76 \\
\hline & & & \\
\hline Gyrations @ Ninitial: 8 & & \\
\hline Gyrations @ N Nesign: 100 & & \\
\hline Gyrations @ N Nax: 160 & & \\
\hline Specific Gravity Stone Bulk $\left(\mathrm{G}_{\mathrm{sb}}\right): 2.658$ & \\
\hline Maximum Density $\left(\mathrm{kg} / \mathrm{m}^{3}\right): 2.473$ & \\
\hline
\end{tabular}




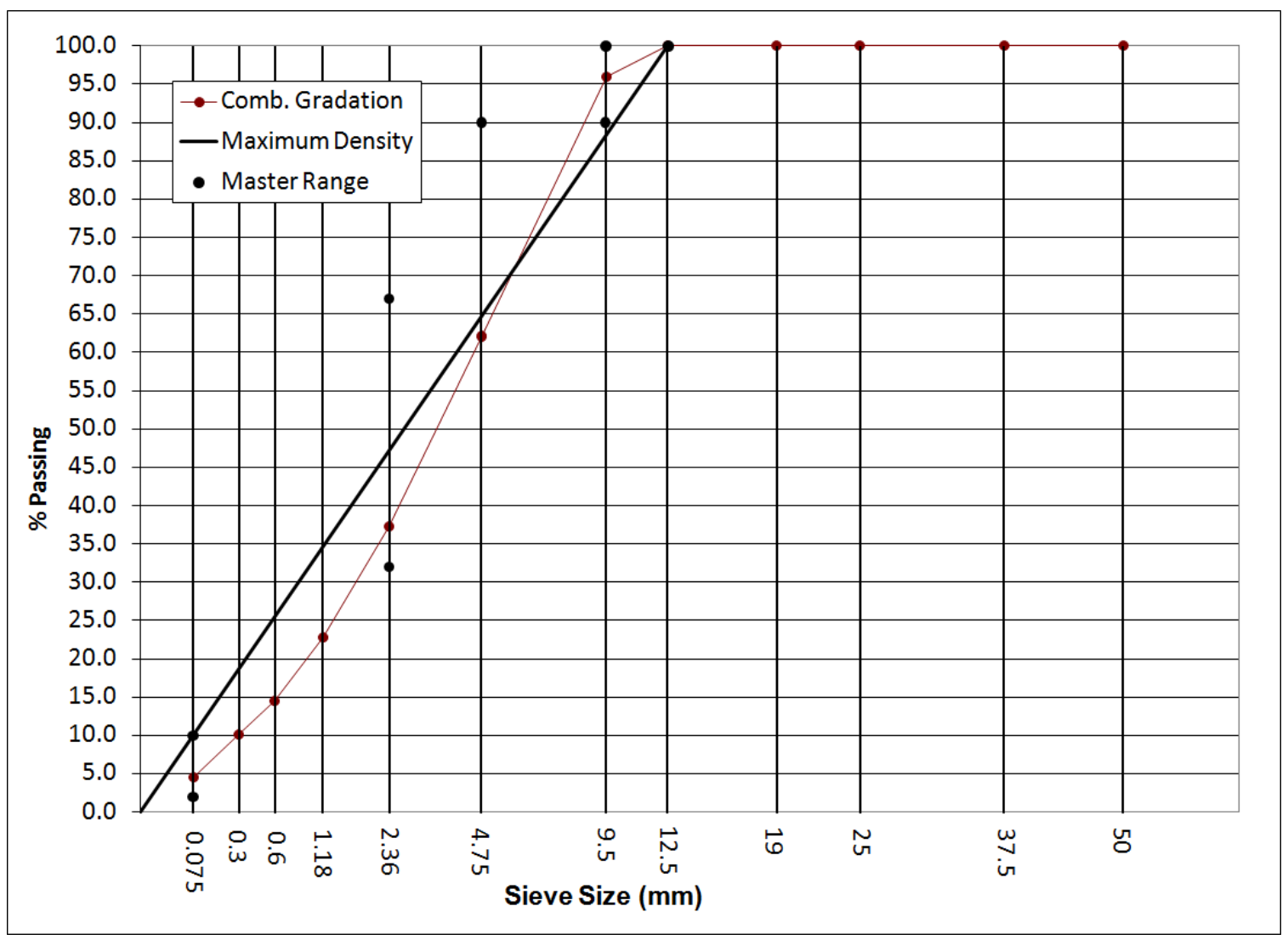

Figure 3.1: Combined Gradation Used During Research

Once aggregate was obtained, it was sieved, washed, dried and placed into individual containers. For each mix, a specified amount of aggregate was weighed and placed in an oven at $165^{\circ} \mathrm{C}\left(329^{\circ} \mathrm{F}\right)$ for 2 hours. Aggregate was then placed in a bucket and the aggregate weight was recorded. An exact amount of binder was added and mixed with the aggregate. The mixed asphalt was placed on a table, separated, and placed into pans for 2 bulk specific gravity $\left(\mathrm{G}_{\mathrm{mb}}\right)$ samples and $1 \mathrm{G}_{\mathrm{mm}}$ sample. The pans were placed in an oven at $153^{\circ} \mathrm{C}\left(307^{\circ} \mathrm{F}\right)$ and conditioned for 2 hours. The $\mathrm{G}_{\mathrm{mm}}$ sample was then spread out on a table to cool. Gyratory results were recorded to analyze how binder content affects compaction effort. The $\mathrm{G}_{\mathrm{mm}}$ sample was then placed in a pycnometer, weighed, filled with water, and air was evacuated using a vacuum. The pycnometer was weighed in water and the $G_{m m}$ was calculated. The dry weight, weight in water, and saturated surface dry (SSD) weight of the $\mathrm{G}_{\mathrm{mb}}$ samples were recorded then next day. The percent air voids (VTM) were calculated from this information and the samples were 
accepted or rejected for further testing. Samples were rejected if air voids were more than $\pm 0.5 \%$ from the target.

\subsection{PERMEABILITY PROCEDURE}

The Florida test method used in this research determines the water conductivity of a laboratory compacted cylindrical specimen or a field core sample obtained from existing pavements. It applies to one-dimensional, laminar flow and it is assumed that Darcy's law is valid. Figure 3.2 shows the permeameter used in this research.

To begin the procedure, the height and diameter of an asphalt specimen was measured and recorded to the nearest $0.5 \mathrm{~mm}$ at three different locations. The samples tested were consistently $75 \mathrm{~mm}$ in height and $150 \mathrm{~mm}$ in diameter.

The asphalt samples were required to reach a saturated state during the permeability test. In order to assist in saturating the samples before the test, the samples were completely submerged in water for one to two hours. Once the samples were saturated, they were removed and the sides were wiped with a towel to remove water.

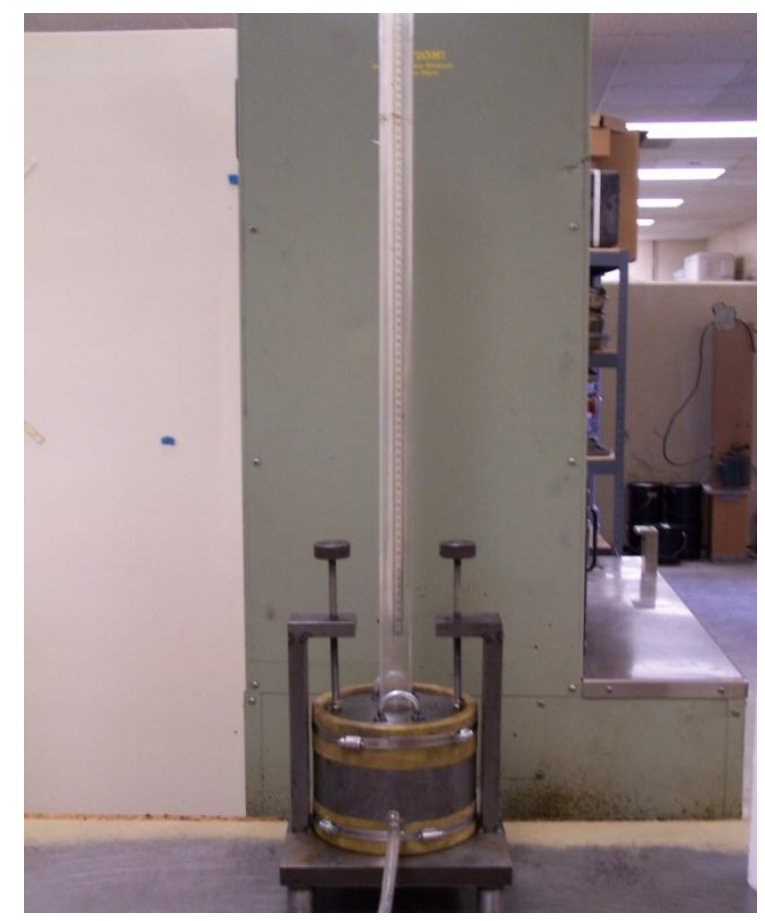

Figure 3.2: HMAC Permeameter Used During Research 
A spatula was then used to apply petroleum jelly to the sides of each sample, Figure 3.3. The petroleum jelly fills the large void spaces on the sides of the samples, which were not representative of the level of compaction of the interior. This allowed water to flow vertically and prevented water from flowing out of the sides of the samples.

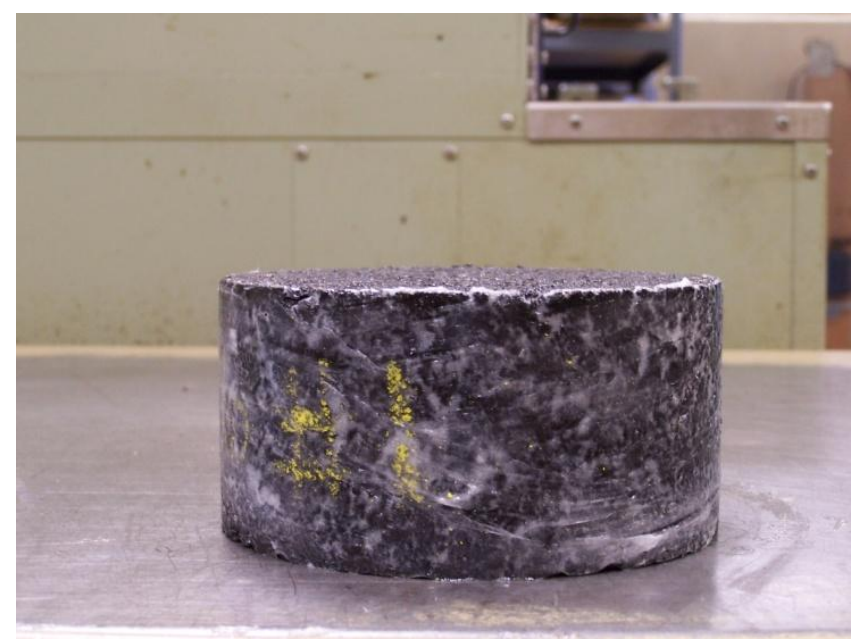

Figure 3.3: Asphalt Sample Coated with Petroleum Jelly

After petroleum jelly was placed on the samples, they were centered on top of the lower pedestal plate, Figure 3.4. The sealing tube line with an elastic membrane was then placed over the specimen and lower pedestal plate, making sure the hose barb fitting was located between the o-rings on the upper cap and lower pedestal plate, Figure 3.5.

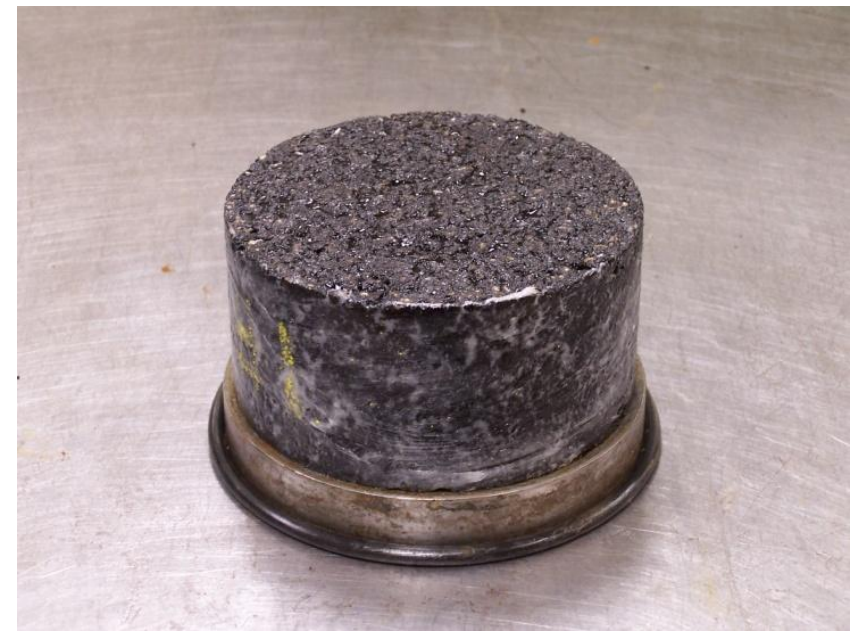

Figure 3.4: Asphalt Sample Placed on Lower Pedestal Plate 


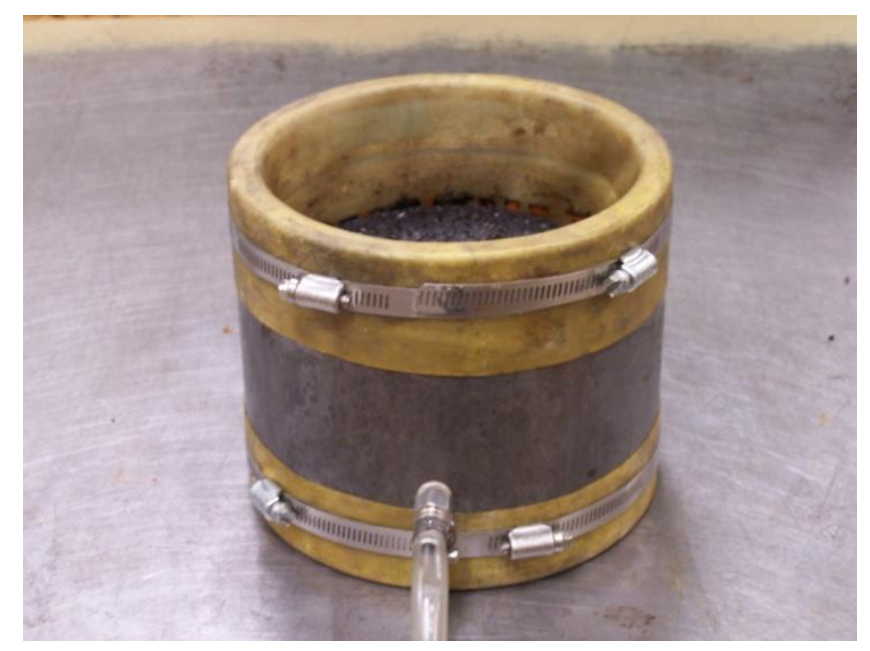

Figure 3.5: Sealing Tube Placed Over Asphalt Sample

The graduated cylinder was placed on top of the asphalt samples and the upper cap assembly was placed on top of the graduated cylinder plate. Two clamp assemblies were evenly tightened onto the upper cap assembly, Figure 3.6. This action sealed the orings against the membrane and sealing tube. The membrane was inflated to $10 \mathrm{psi}$ and the pressure was maintained throughout the test.

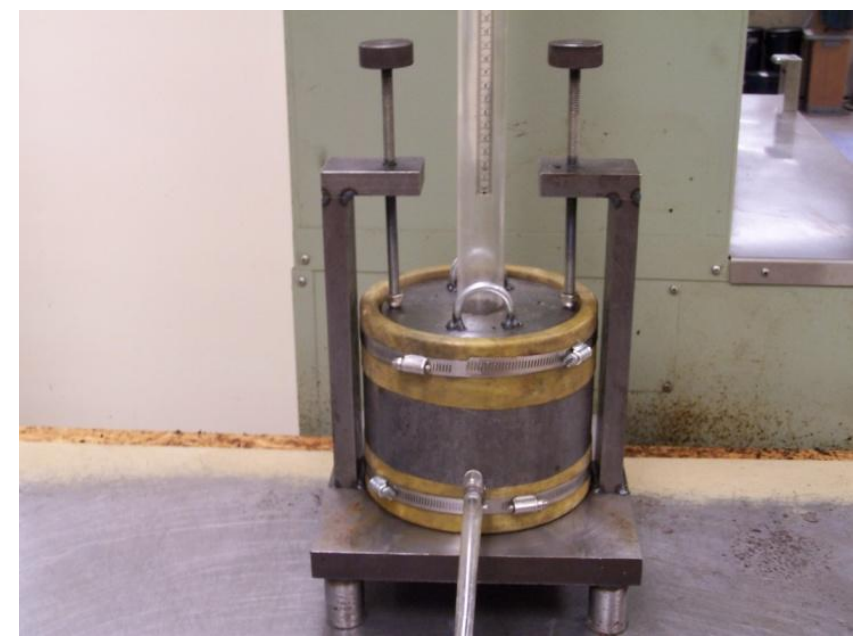

Figure 3.6: Clamp Assemblies Placed on Graduated Cylinder Plate

The graduated cylinder was filled with water approximately half way and rocked back and forth to dislodge any trapped air from the upper cavity. The cylinder was filled to a level above the upper timing mark after all air was removed. The timer was started when the bottom of the meniscus of water reached the upper timing mark. The timer was 
stopped when the bottom of the meniscus reached the lower timing mark. The time was recorded to the nearest second. This test was performed three consecutive times until the difference between the first and third test was less than four percent. The temperature was recorded to the nearest $0.1^{\circ} \mathrm{C}\left(0.2^{\circ} \mathrm{F}\right)$.

The coefficient of permeability, $\mathrm{k}$, is calculated using equation 2.3

\subsection{INDIRECT TENSION TEST PROCEDURE}

An indirect tension (IDT) strength test was performed to evaluate the rut resistance of the hot mix asphalt concrete (HMAC) design used in this research. The samples were prepared by placing them in an oven for one to two hours at $61^{\circ} \mathrm{C}$. This temperature was $9^{\circ} \mathrm{C}$ lower than the upper temperature rating of the binder.

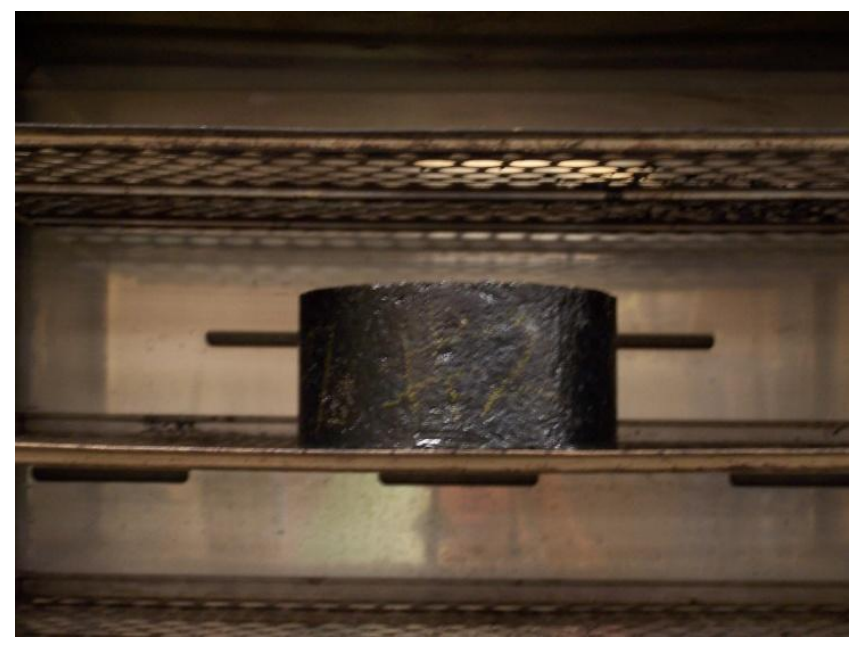

Figure 3.7: Asphalt Sample in Oven at $61^{\circ} \mathrm{C}$

Following temperature conditioning, the samples were placed in the testing apparatus and immediately loaded to failure at a loading rate of $50 \mathrm{~mm} / \mathrm{min}$. The IDT strength was calculated using equation 2.4. After the IDT strength was calculated, the estimated maximum allowable design traffic for the mixture was estimated using equation 2.5 . 


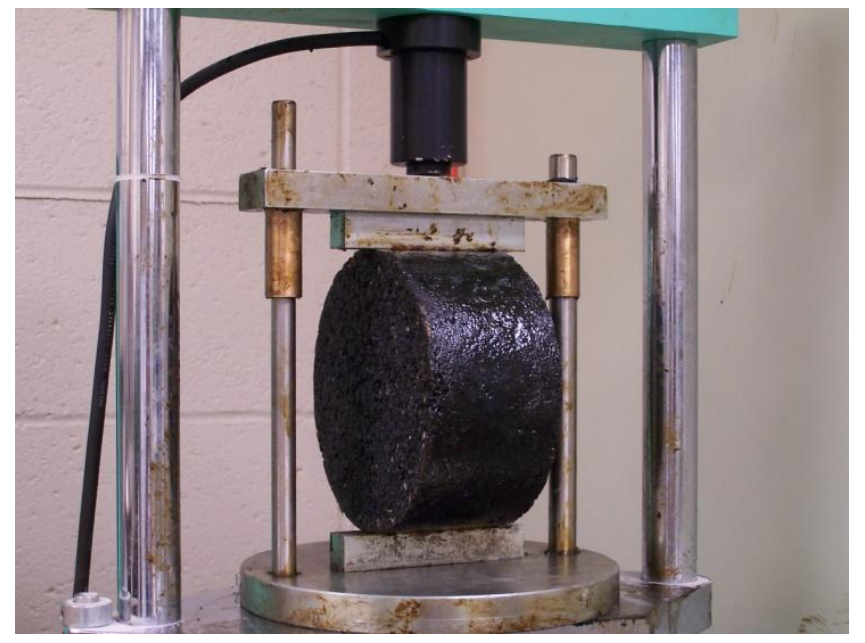

Figure 3.8: Asphalt Sample Placed in IDT Testing Apparatus

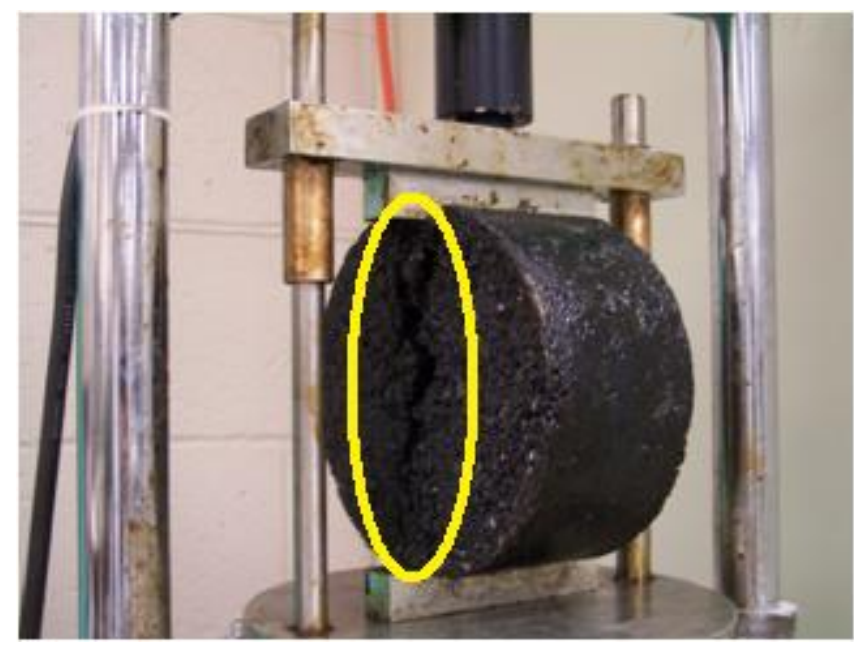

Figure 3.9: Failure of Asphalt Sample

\subsection{METHOD OF ANALYSIS}

Gyration data from the gyratory compactor were recorded and analyzed using Microsoft Excel. The data were used to observe how binder content affected the compaction effort needed to achieve the desired air void level. Permeability data were recorded from the permeameter and analyzed using Microsoft Excel and statistical analysis software (SAS). IDT strength data was recorded and analyzed using Microsoft Excel and SAS. A 4x4 factorial design was used to observe the significance binder content and air void levels have on permeability and maximum allowable traffic. A 5 
percent confidence level was used to identify significance factors and interactions of permeability and maximum allowable traffic. The primary factors of these tests were air voids and binder content. 


\section{CHAPTER 4: RESULTS AND ANALYSIS}

\subsection{INTRODUCTION}

Three factors affected by binder content were tested during this research:

- Compaction effort

- Permeability

- Maximum allowable traffic estimated for rutting

The results were analyzed after all the samples were tested as described in Chapter 3. Data from all factors were analyzed using Microsoft Excel for this research. In addition, permeability and maximum allowable traffic data were analyzed using a $4 x 4$ factorial design. Binder content and air void levels were examined using statistical analysis software (SAS) to observe the significance they have on permeability and maximum allowable traffic.

\subsection{COMPACTION RESULTS}

The number of gyrations that were needed to compact the asphalt samples in the gyratory compactor to a height of $75 \mathrm{~mm}$ was recorded and analyzed. The results verify that when binder content increased, the number of gyrations decreases. Table 4.1 presents the gyratory results for all asphalt samples used in this research. Figures 4.1 to 4.4 present the gyrations for asphalt samples at each binder content. Figure 4.5 presents the gyrations for all average binder contents. This figure demonstrates that compaction effort, to achieve a specified level of density, reduces as asphalt content increases. The West Virginia Division of Highways (WVDOH) implemented research recommendations which should result in high design binder content. This should improve the ability of contractors to achieve density during construction (Zaniewski et al., 2005). 
Table 4.1: Gyrations for All Asphalt Samples

\begin{tabular}{|c|c|c|c|c|c|c|}
\hline & \multicolumn{2}{|c|}{ Pill 1} & \multicolumn{2}{|c|}{ Pill 2} & \multirow[b]{2}{*}{$\begin{array}{c}\text { Average } \\
\text { Air } \\
\text { Content } \\
(\%) \\
\end{array}$} & \multirow[b]{2}{*}{$\begin{array}{c}\text { Average } \\
\text { Gyrations }\end{array}$} \\
\hline $\begin{array}{c}\text { Binder } \\
\text { Content } \\
(\%)\end{array}$ & $\begin{array}{c}\text { Air } \\
\text { Content } \\
(\%)\end{array}$ & Gyrations & $\begin{array}{c}\text { Air } \\
\text { Content } \\
(\%)\end{array}$ & Gyrations & & \\
\hline \multirow[t]{4}{*}{5.2} & 3.9 & 187 & 3.9 & 181 & 3.9 & 184 \\
\hline & 6.4 & 115 & 6.0 & 123 & 6.2 & 119 \\
\hline & 7.6 & 56 & 7.7 & 58 & 7.7 & 57 \\
\hline & 9.5 & 39 & 9.5 & 42 & 9.5 & 41 \\
\hline \multirow[t]{4}{*}{5.7} & 3.8 & 131 & 3.8 & 133 & 3.8 & 132 \\
\hline & 6.5 & 74 & 6.1 & 76 & 6.3 & 75 \\
\hline & 8.3 & 45 & 8.2 & 50 & 8.3 & 48 \\
\hline & 10.4 & 26 & 10.1 & 25 & 10.3 & 26 \\
\hline \multirow[t]{4}{*}{6.2} & 4.3 & 75 & 4.1 & 85 & 4.2 & 80 \\
\hline & 6.5 & 42 & 6.2 & 44 & 6.4 & 43 \\
\hline & 7.7 & 39 & 7.8 & 38 & 7.8 & 39 \\
\hline & 9.6 & 16 & 9.6 & 18 & 9.6 & 17 \\
\hline \multirow[t]{4}{*}{6.7} & 4.5 & 52 & 4.3 & 61 & 4.4 & 57 \\
\hline & 6.5 & 36 & 6.4 & 39 & 6.5 & 38 \\
\hline & 8.5 & 21 & 8.3 & 23 & 8.4 & 22 \\
\hline & 9.9 & 15 & 9.8 & 17 & 9.9 & 16 \\
\hline
\end{tabular}

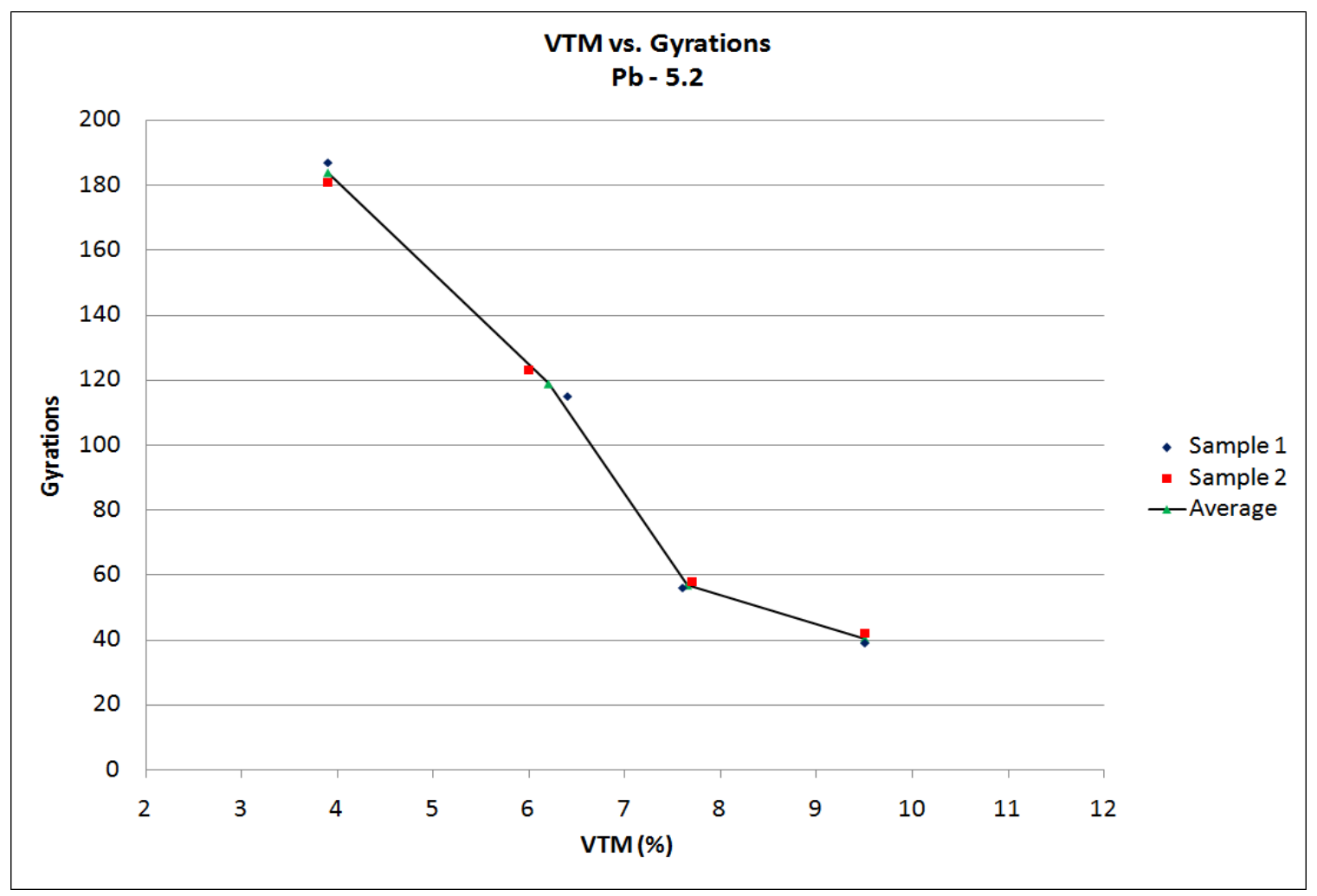

Figure 4.1: Gyrations at 5.2 Percent Binder 


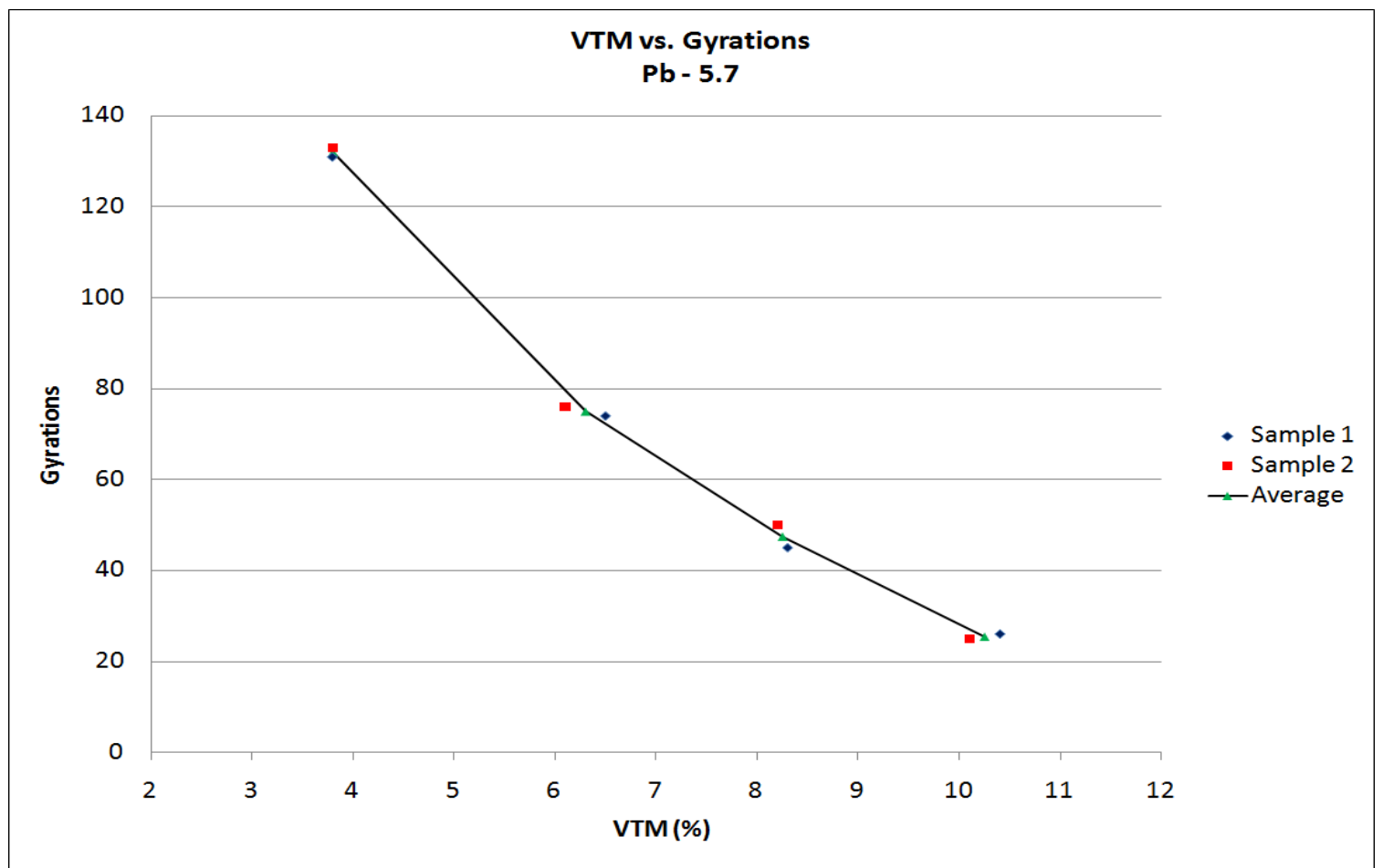

Figure 4.2: Gyrations at 5.7 Percent Binder

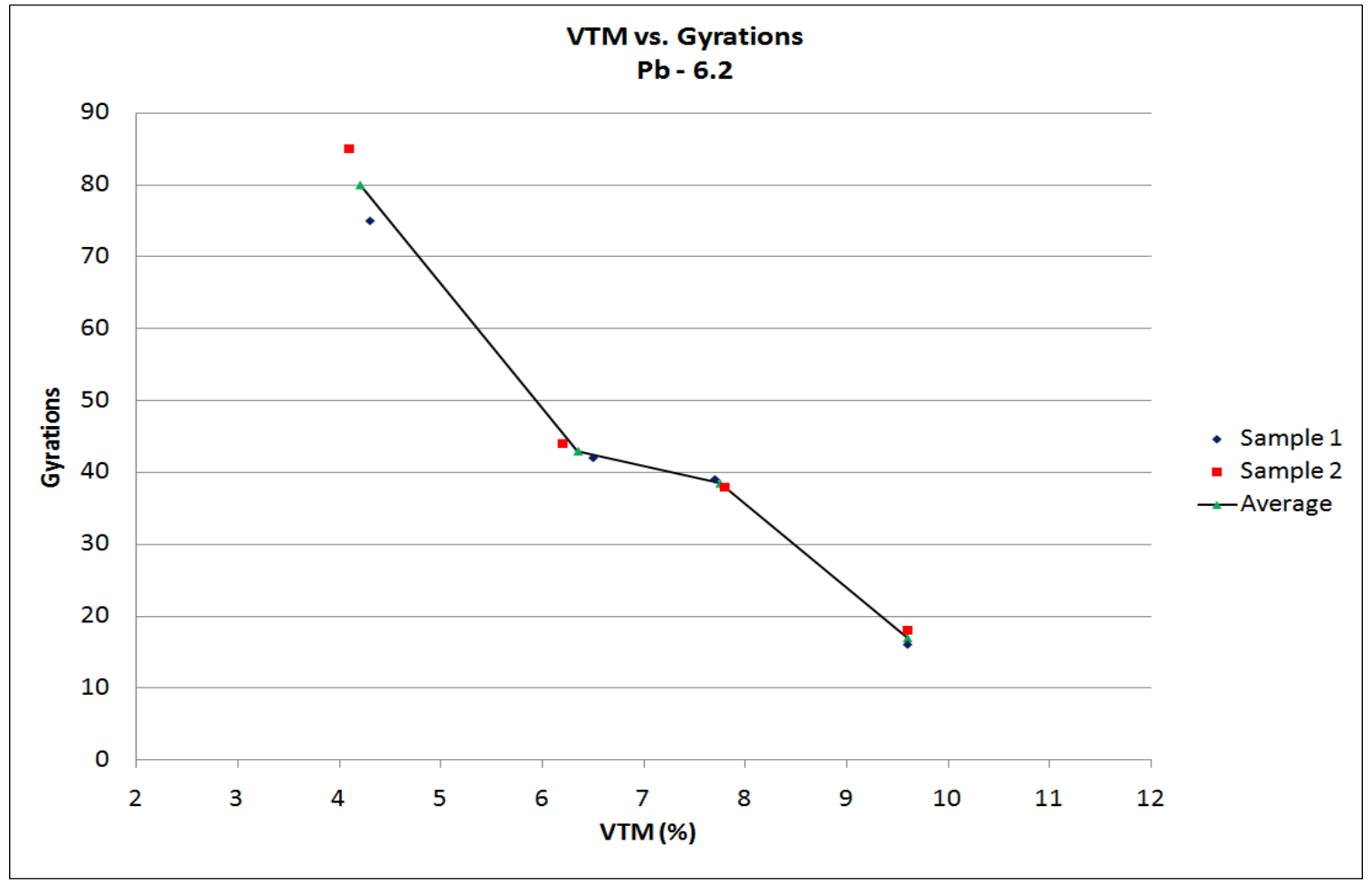

Figure 4.3: Gyrations at 6.2 Percent Binder 


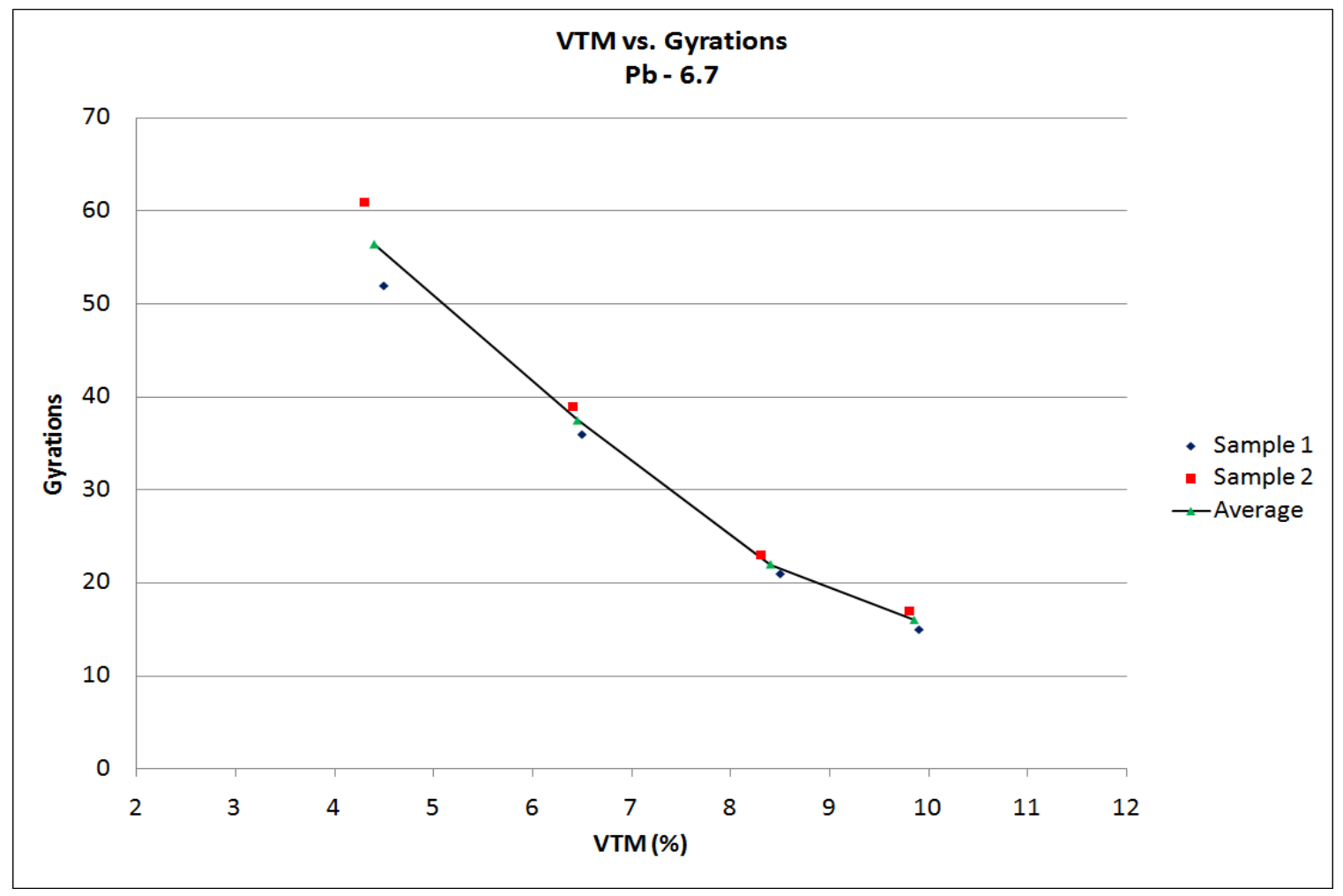

Figure 4.4: Gyrations at 6.7 Percent Binder

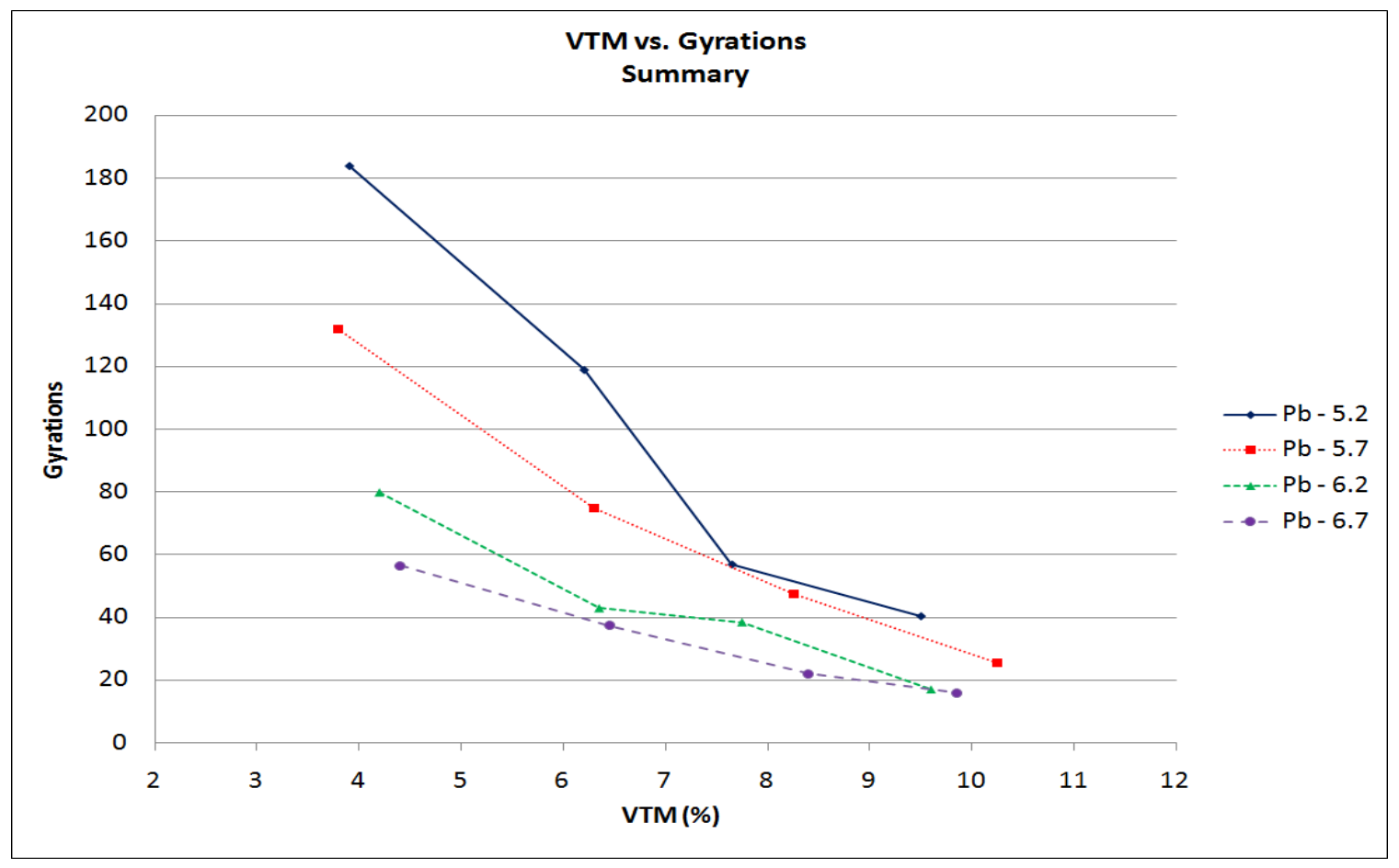

Figure 4.5: Summary of Average Gyrations 


\subsection{PERMEABILITY RESULTS}

Asphalt samples were tested at four air void levels to observe how binder content affects permeability. Results confirm that when air void levels increase, permeability also increases; however, permeability is shown to decrease when binder content increases. Permeability remains almost constant from 4 to 7 percent air content. Permeability is shown to drastically increase at 8 percent air content and above. Table 4.2 presents the permeability results for all asphalt samples used in this research. Figures 4.6 to 4.9 present how permeability is affected by binder content at various air void levels. Figure 4.10 presents a summary of average permeability values at each binder content.

A statistical analysis was performed using a $4 \times 4$ factorial design. A 5 percent confidence level was used to identify significant factors and interactions. The primary factors of air voids and percent binder were significant. In addition, their interaction was significant. The sign on the coefficient estimate given in Figure 4.11 demonstrates increasing air voids increases permeability and increasing binder content reduces permeability as would be expected. Figure 4.11 presents the results of the statistical analysis. 
Table 4.2: Permeability Results for All Asphalt Samples

\begin{tabular}{|c|c|c|c|c|c|c|}
\hline & \multicolumn{2}{|c|}{ Pill 1} & \multicolumn{2}{|c|}{ Pill 2} & \multirow[b]{2}{*}{$\begin{array}{c}\text { Average } \\
\text { Air Content } \\
(\%)\end{array}$} & \multirow[b]{2}{*}{$\begin{array}{c}\text { Average } \\
\text { Permeability } \\
\left(10^{-5} \mathrm{~cm} / \mathrm{s}\right)\end{array}$} \\
\hline $\begin{array}{c}\text { Binder Content } \\
(\%) \\
\end{array}$ & $\begin{array}{c}\text { Air Content } \\
(\%)\end{array}$ & $\begin{array}{c}\text { Permeability } \\
\left(10^{-5} \mathrm{~cm} / \mathrm{s}\right)\end{array}$ & $\begin{array}{c}\text { Air Content } \\
(\%) \\
\end{array}$ & $\begin{array}{l}\text { Permeability } \\
\left(10^{-5} \mathrm{~cm} / \mathrm{s}\right)\end{array}$ & & \\
\hline \multirow[t]{4}{*}{5.2} & 3.9 & 0.22 & 3.9 & 0.18 & 3.9 & 0.20 \\
\hline & 6.4 & 0.95 & 6.0 & 0.80 & 6.2 & 0.88 \\
\hline & 7.6 & 23.04 & 7.7 & 23.67 & 7.7 & 23.36 \\
\hline & 9.5 & 821.58 & 9.5 & 802.99 & 9.5 & 812.29 \\
\hline \multirow[t]{4}{*}{5.7} & 3.8 & 0.15 & 3.8 & 0.24 & 3.8 & 0.20 \\
\hline & 6.5 & 0.69 & 6.1 & 0.49 & 6.3 & 0.59 \\
\hline & 8.3 & 21.76 & 8.2 & 21.63 & 8.3 & 21.70 \\
\hline & 10.4 & 748.88 & 10.1 & 692.09 & 10.3 & 720.49 \\
\hline \multirow[t]{4}{*}{6.2} & 4.3 & 0.15 & 4.1 & 0.11 & 4.2 & 0.13 \\
\hline & 6.5 & 0.51 & 6.2 & 0.33 & 6.4 & 0.42 \\
\hline & 7.7 & 11.11 & 7.8 & 11.38 & 7.8 & 11.25 \\
\hline & 9.6 & 315.36 & 9.6 & 318.62 & 9.6 & 316.99 \\
\hline \multirow[t]{4}{*}{6.7} & 4.5 & 0.11 & 4.3 & 0.04 & 4.4 & 0.08 \\
\hline & 6.5 & 0.31 & 6.4 & 0.24 & 6.5 & 0.28 \\
\hline & 8.5 & 11.11 & 8.3 & 6.81 & 8.4 & 8.96 \\
\hline & 9.9 & 198.34 & 9.8 & 188.41 & 9.9 & 193.38 \\
\hline
\end{tabular}

Permeability vs. VTM

$\mathrm{Pb}-\mathbf{5 . 2}$

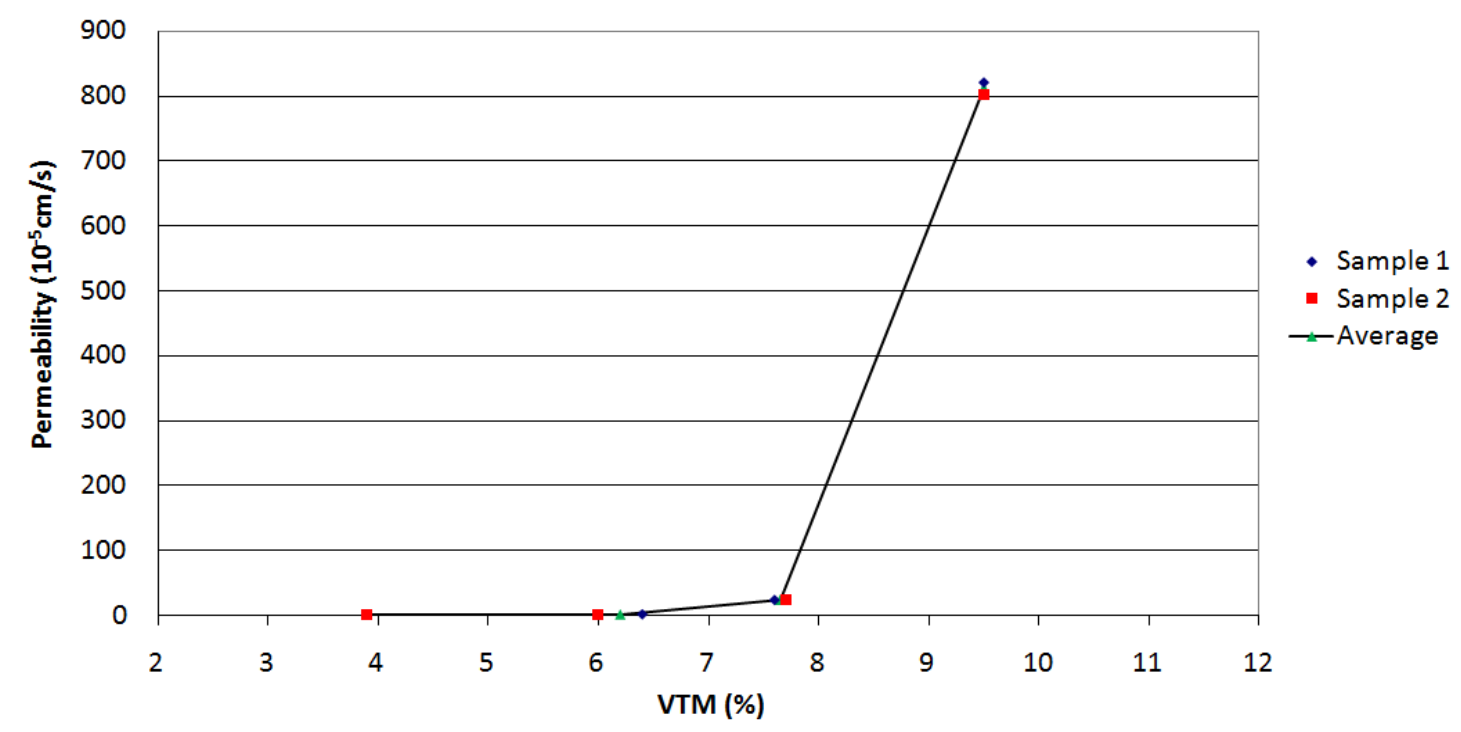

Figure 4.6: Permeability at 5.2 Percent Binder 


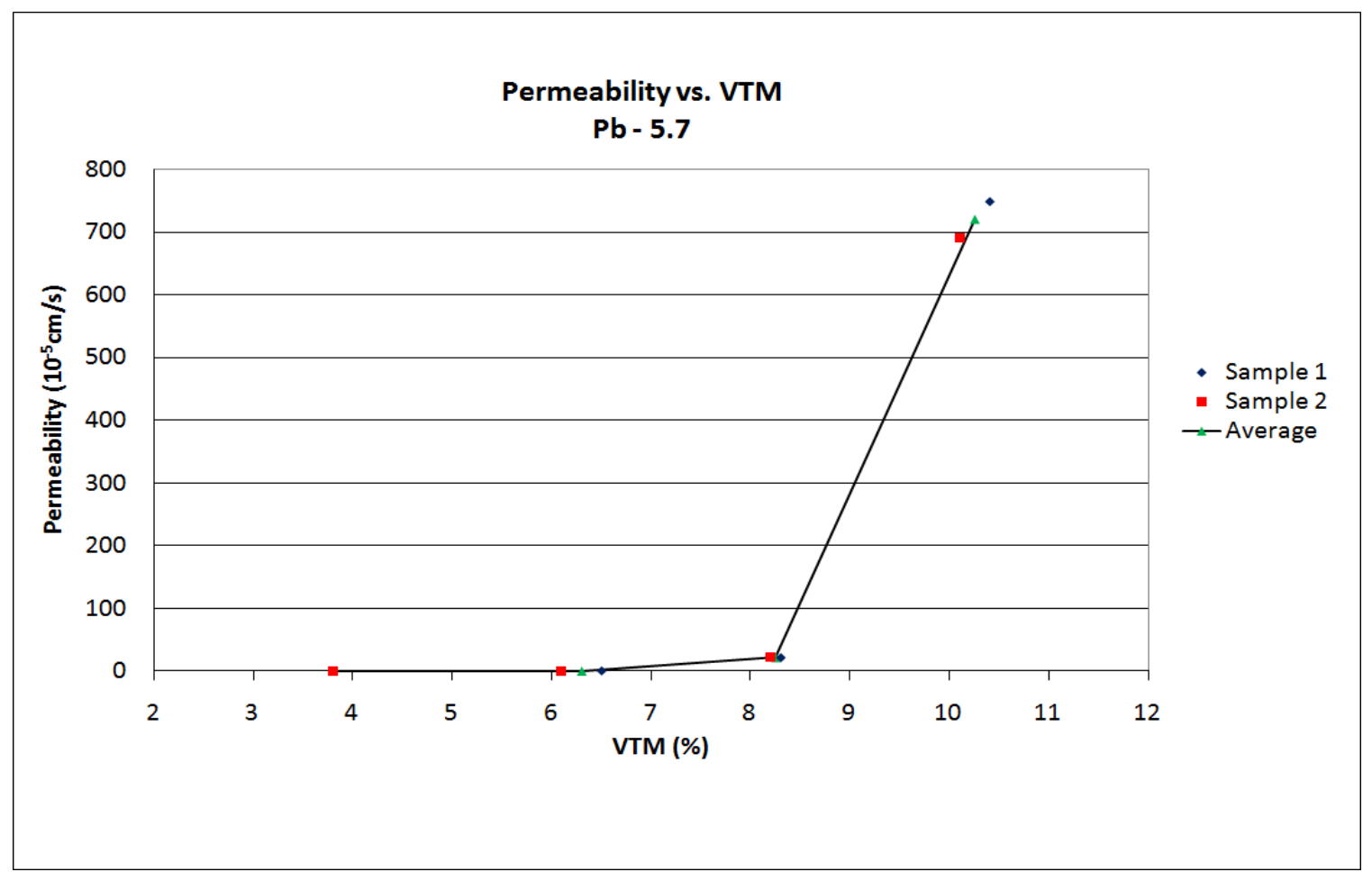

Figure 4.7: Permeability at 5.7 Percent Binder

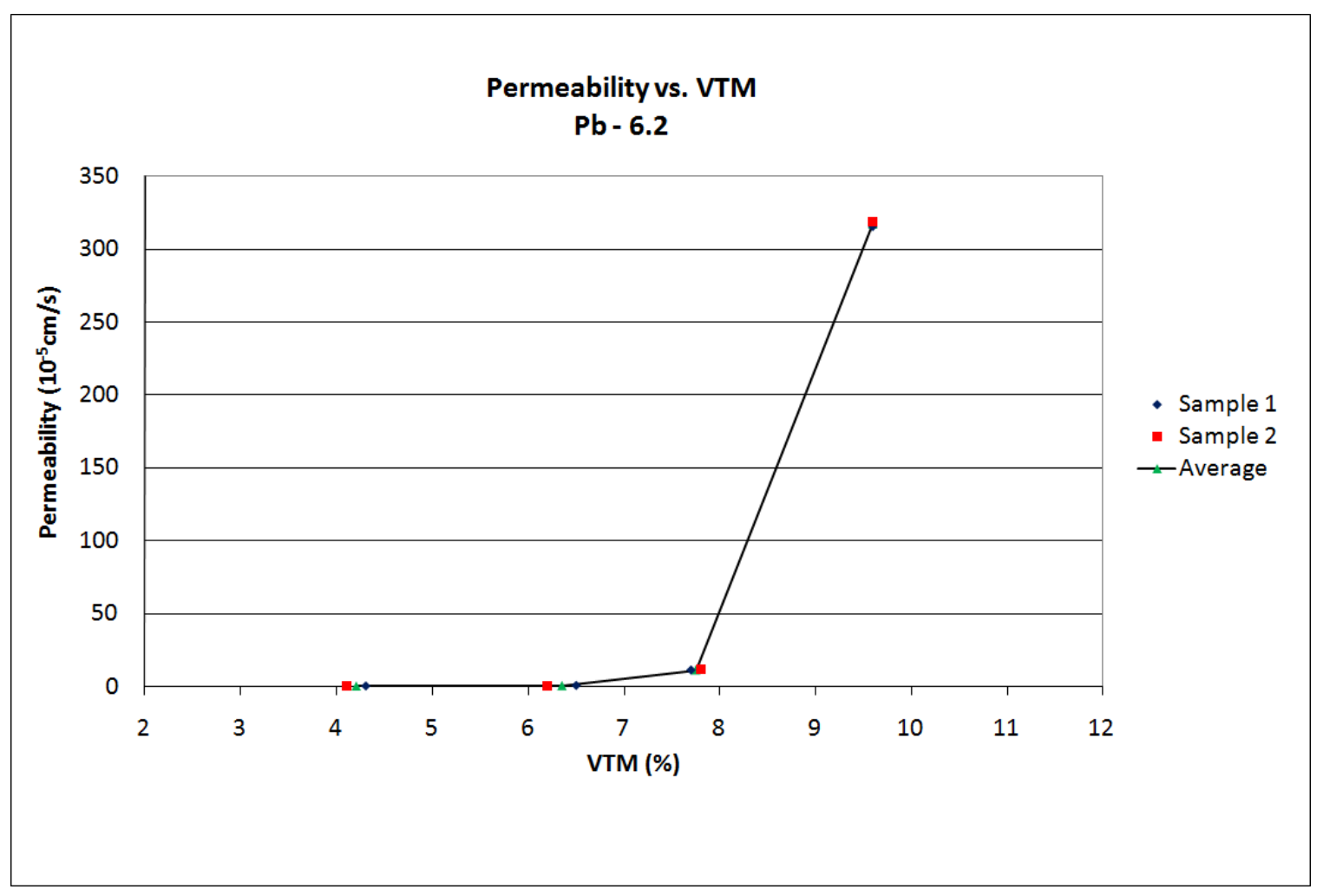

Figure 4.8: Permeability at 6.2 Percent Binder 


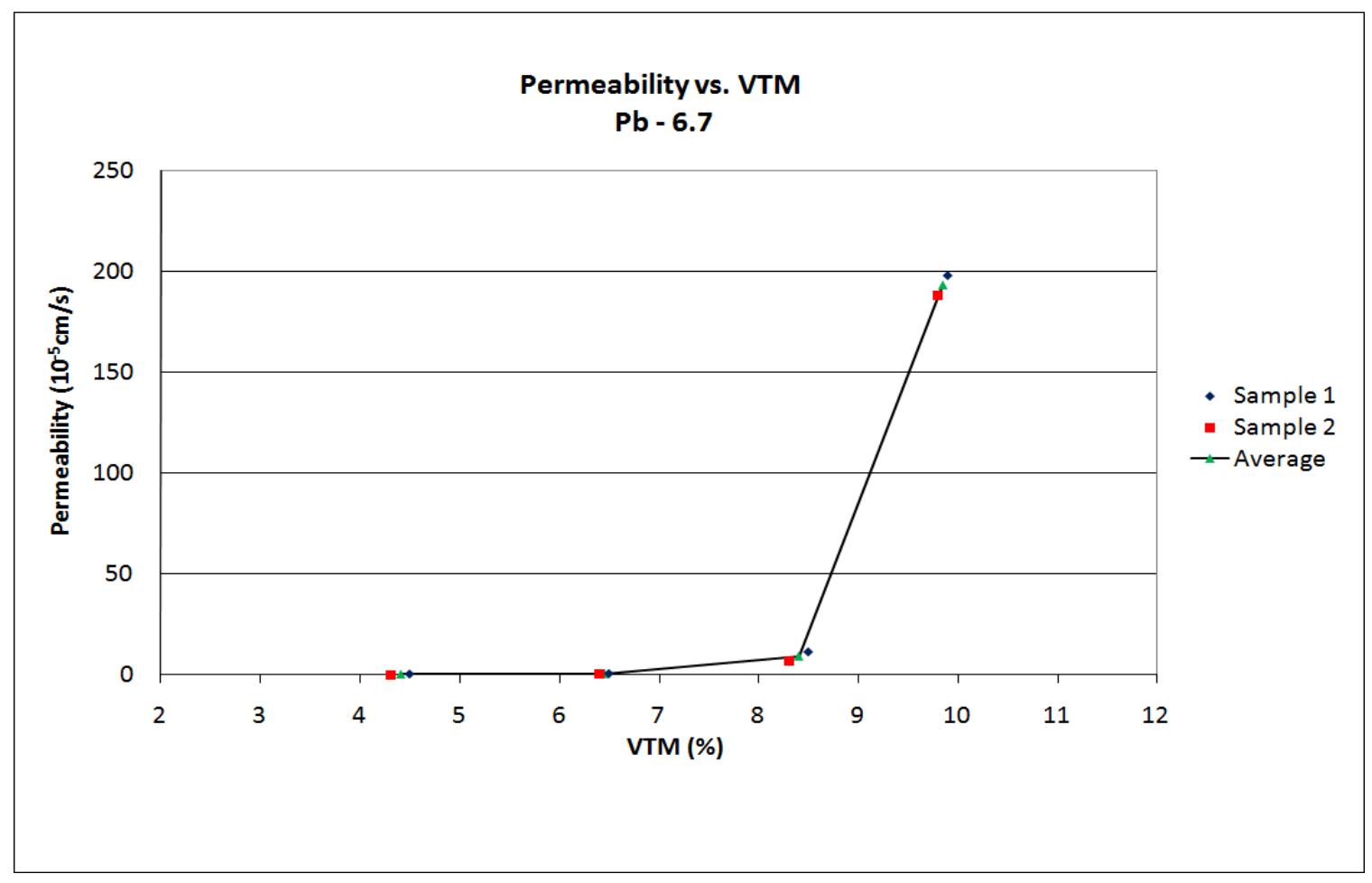

Figure 4.9: Permeability at 6.7 Percent Binder

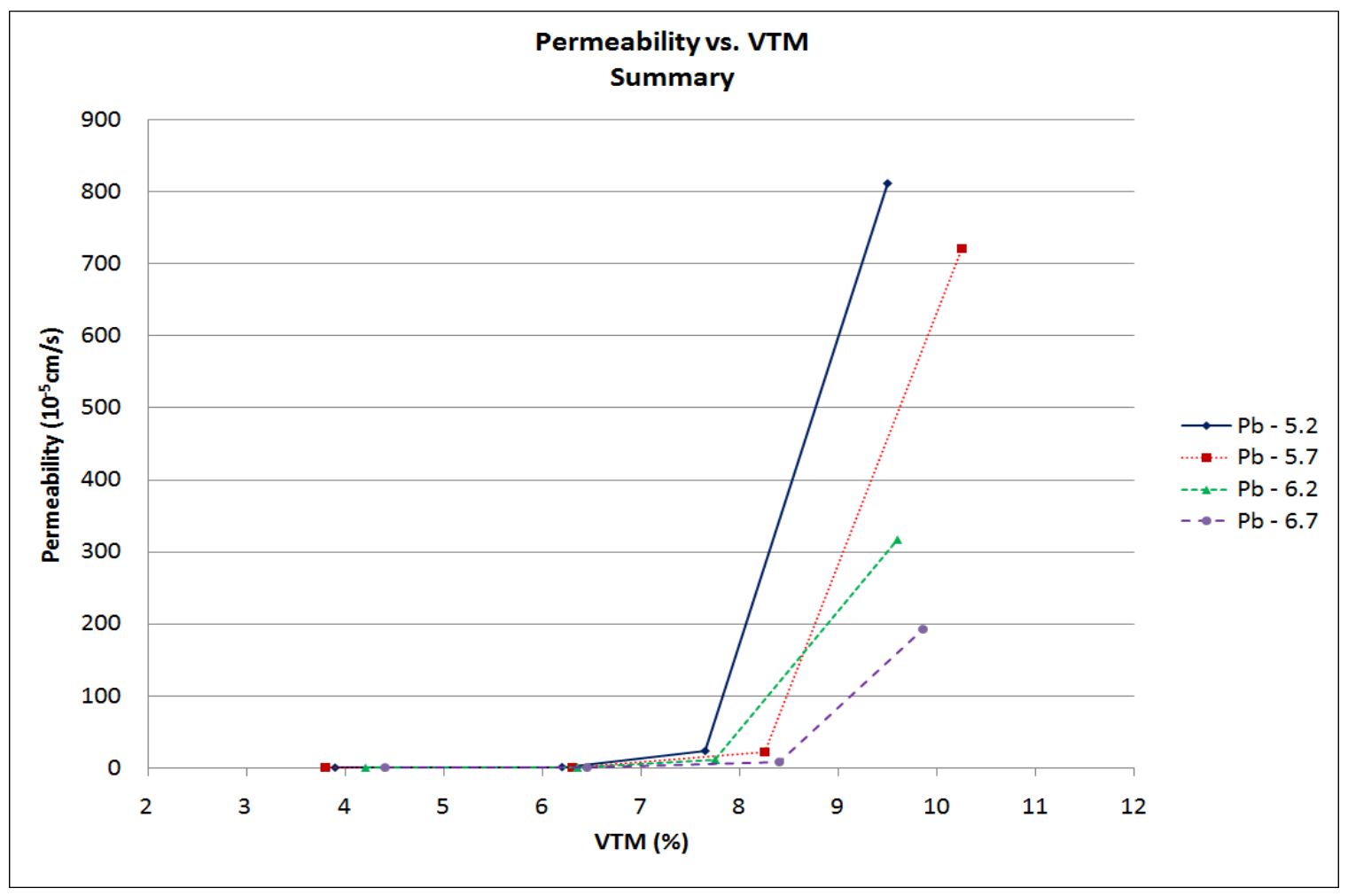

Figure 4.10: Summary of Average Permeability Values 


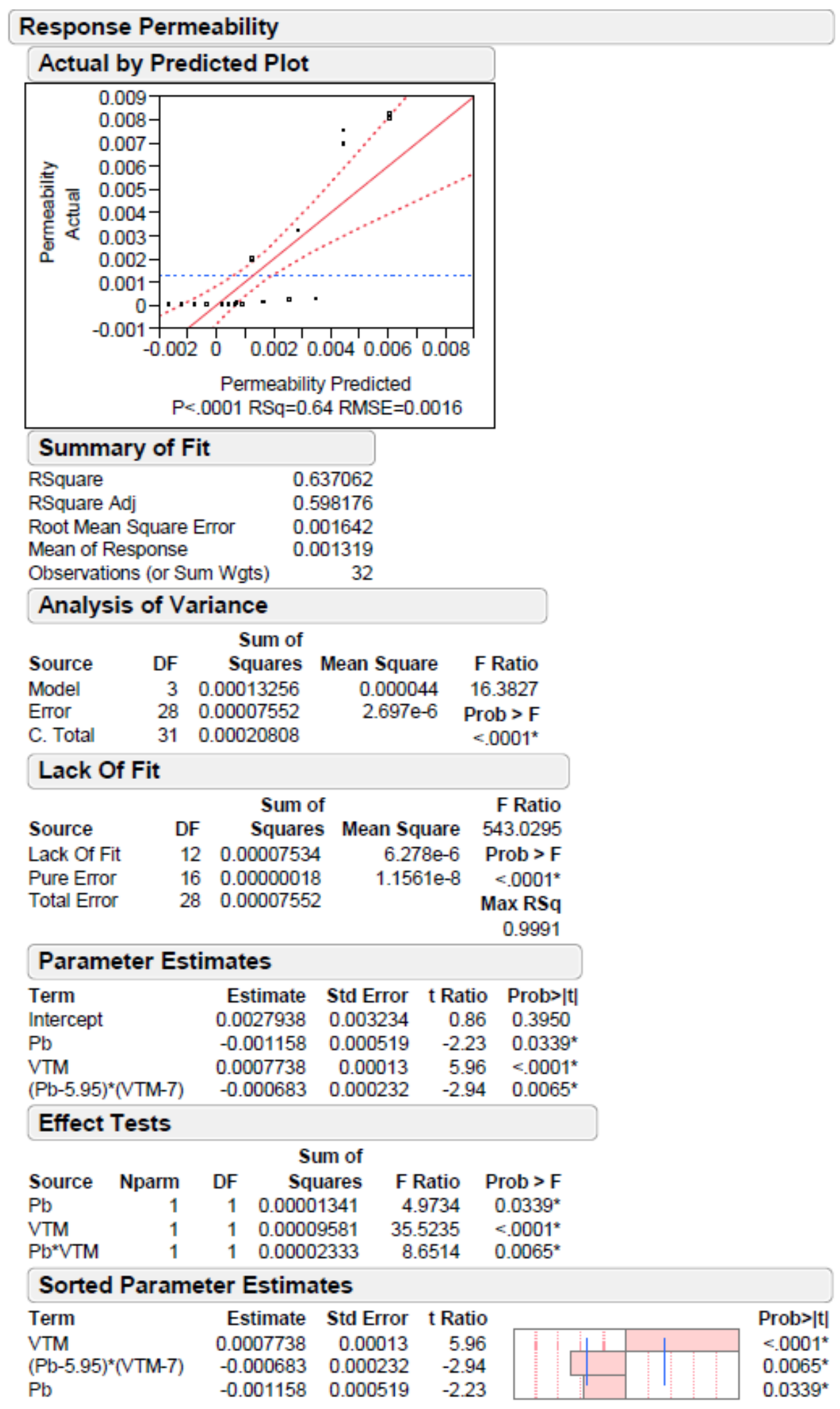

Figure 4.11: Permeability Statistical Analysis Results 


\subsection{INDIRECT TENSION TEST RESULTS}

An IDT strength test was performed to analyze the rutting resistance of the mix design. The result of this test demonstrates that when binder content is increased, the estimated maximum allowable traffic decreases. Table 4.3 presents the estimated maximum allowable traffic for all asphalt samples. Figures 4.12 to 4.15 present how binder content affects estimated maximum allowable traffic at various air void levels. Figure 4.16 presents the average estimated maximum allowable traffic at each binder content. Included in this graph is the specified ESAL range (3 to 30 million) of the mix design used in this research. Samples containing 5.2 and 5.7 percent binder stayed within this range from 4 to 8 percent air content. Samples containing 6.2 and 6.7 percent binder fell below the minimum ESAL range from 5 to 10 percent air content.

A statistical analysis was performed using a $4 \times 4$ factorial design. A 5 percent confidence level was used to identify significant factors and interactions. The primary factors of air voids and percent binder were significant. In addition, their interaction was significant. The sign on the coefficient estimate given in Figure 4.17 demonstrates increasing air voids reduces estimated maximum allowable traffic and increasing binder content also reduces maximum allowable traffic as would be expected. Figure 4.17 presents the statistical analysis results of the IDT strength test.

Figure 4.16 demonstrates that the estimated rutting potential increases as asphalt content and air voids increases. This is compatible with expectation from the literature. If the Christensen (2007) model, equation 3.3, is correct, Figure 4.16 demonstrates that care must be used when implementing specifications that will increase asphalt content. 
Table 4.3: Estimated Maximum Allowable Traffic for All Asphalt Samples

\begin{tabular}{|c|c|c|c|c|c|c|}
\hline & \multicolumn{2}{|c|}{ Pill 1} & \multicolumn{2}{|c|}{ Pill 2} & \multirow[b]{2}{*}{$\begin{array}{c}\text { Average } \\
\text { Air } \\
\text { Content } \\
(\%)\end{array}$} & \multirow[b]{2}{*}{$\begin{array}{c}\text { Average } \\
\text { ESALs } \\
\text { (Millions) }\end{array}$} \\
\hline $\begin{array}{c}\text { Binder } \\
\text { Content } \\
(\%)\end{array}$ & $\begin{array}{c}\text { Air } \\
\text { Content } \\
(\%)\end{array}$ & $\begin{array}{c}\text { ESALs } \\
\text { (Millions) }\end{array}$ & $\begin{array}{c}\text { Air } \\
\text { Content } \\
(\%)\end{array}$ & $\begin{array}{c}\text { ESALs } \\
\text { (Millions) }\end{array}$ & & \\
\hline \multirow[t]{4}{*}{5.2} & 3.9 & 53 & 3.9 & 46 & 3.9 & 50 \\
\hline & 6.4 & 31 & 6.0 & 35 & 6.2 & 33 \\
\hline & 7.6 & 12 & 7.7 & 23 & 7.7 & 18 \\
\hline & 9.5 & 7 & 9.5 & 7 & 9.5 & 7 \\
\hline \multirow[t]{4}{*}{5.7} & 3.8 & 12 & 3.8 & 17 & 3.8 & 15 \\
\hline & 6.5 & 9 & 6.1 & 10 & 6.3 & 9 \\
\hline & 8.3 & 5 & 8.2 & 3 & 8.3 & 4 \\
\hline & 10.4 & 2 & 10.1 & 2 & 10.3 & 2 \\
\hline \multirow[t]{4}{*}{6.2} & 4.3 & 4 & 4.1 & 6 & 4.2 & 5 \\
\hline & 6.5 & 2 & 6.2 & 3 & 6.4 & 2 \\
\hline & 7.7 & 1 & 7.8 & 2 & 7.8 & 1 \\
\hline & 9.6 & 1 & 9.6 & 1 & 9.6 & 1 \\
\hline \multirow[t]{4}{*}{6.7} & 4.5 & 3 & 4.3 & 3 & 4.4 & 3 \\
\hline & 6.5 & 1 & 6.4 & 1 & 6.5 & 1 \\
\hline & 8.5 & 1 & 8.3 & 1 & 8.4 & 1 \\
\hline & 9.9 & 1 & 9.8 & 1 & 9.9 & 1 \\
\hline
\end{tabular}

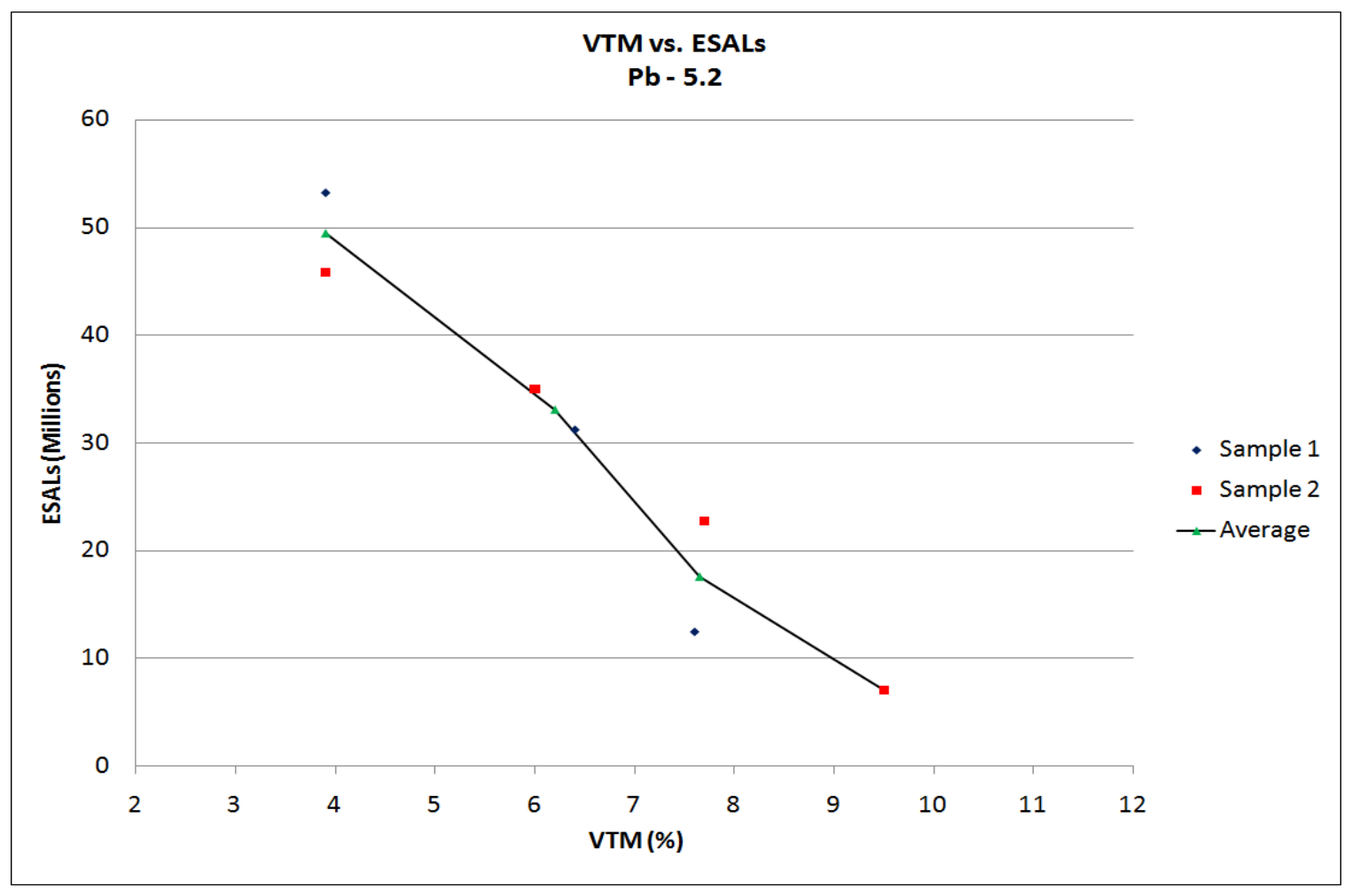

Figure 4.12: Estimated Maximum Allowable Traffic at 5.2 Percent Binder 


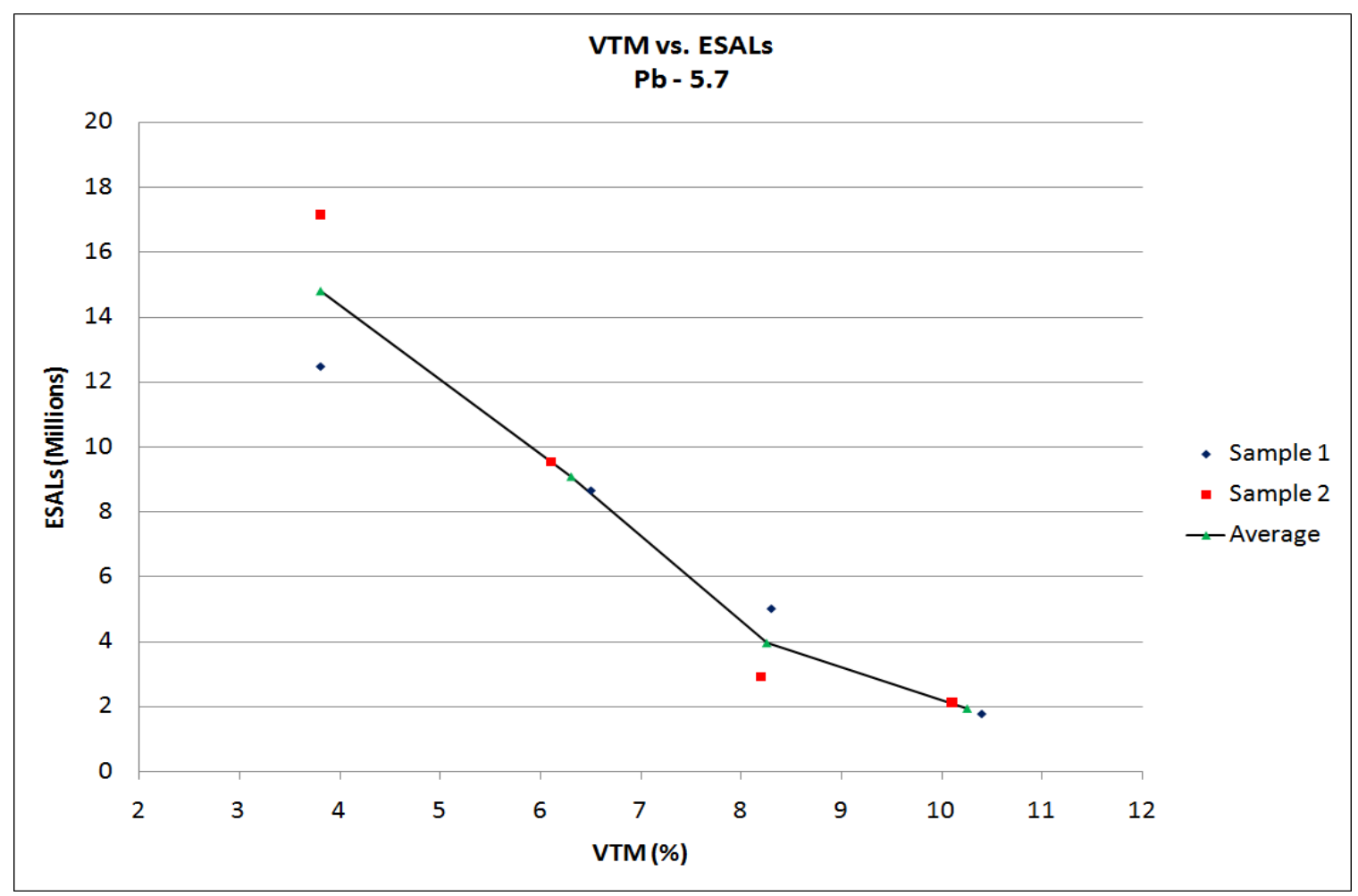

Figure 4.13: Estimated Maximum Allowable Traffic at 5.7 Percent Binder

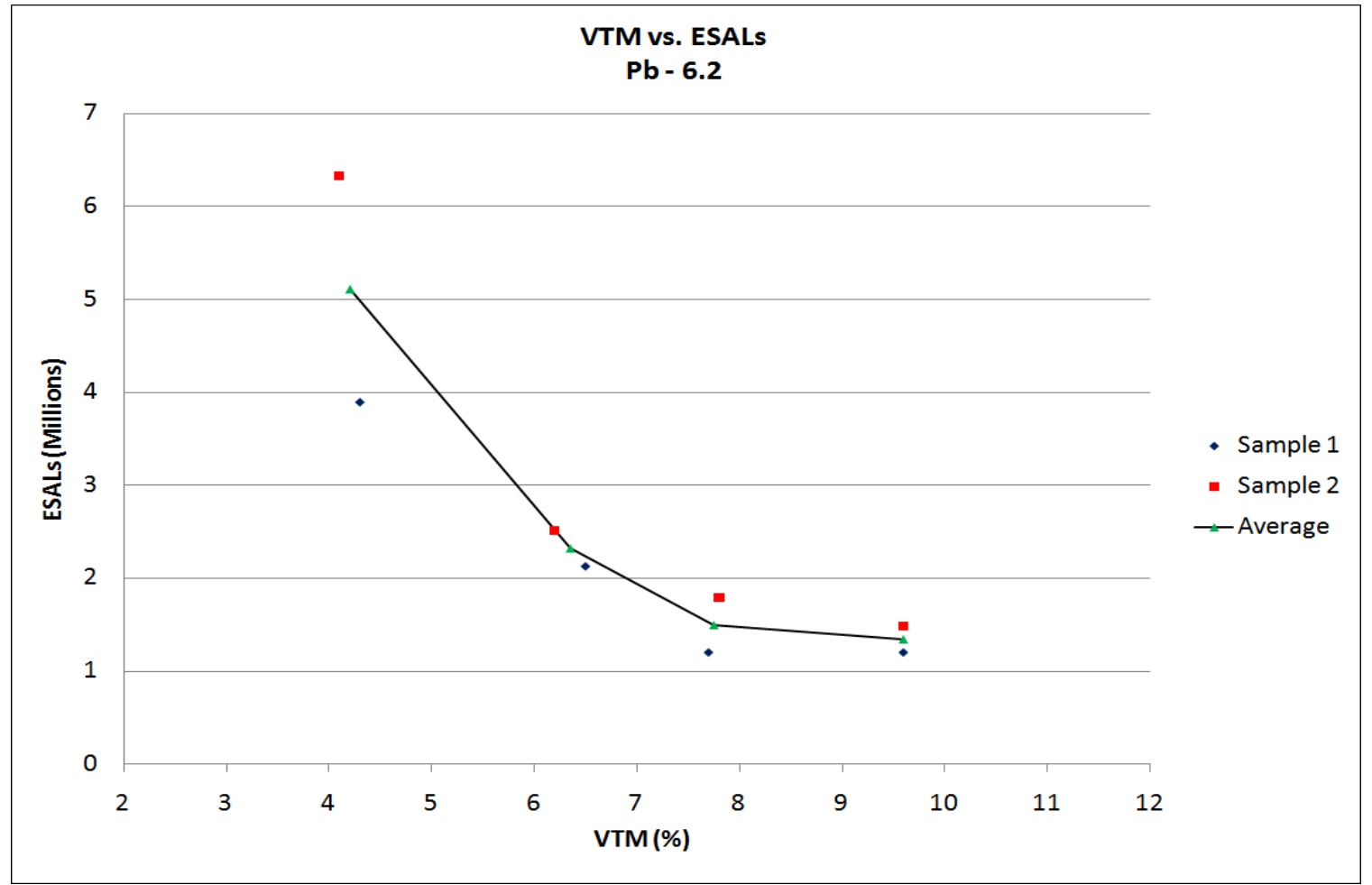

Figure 4.14: Estimated Maximum Allowable Traffic at 6.2 Percent Binder 


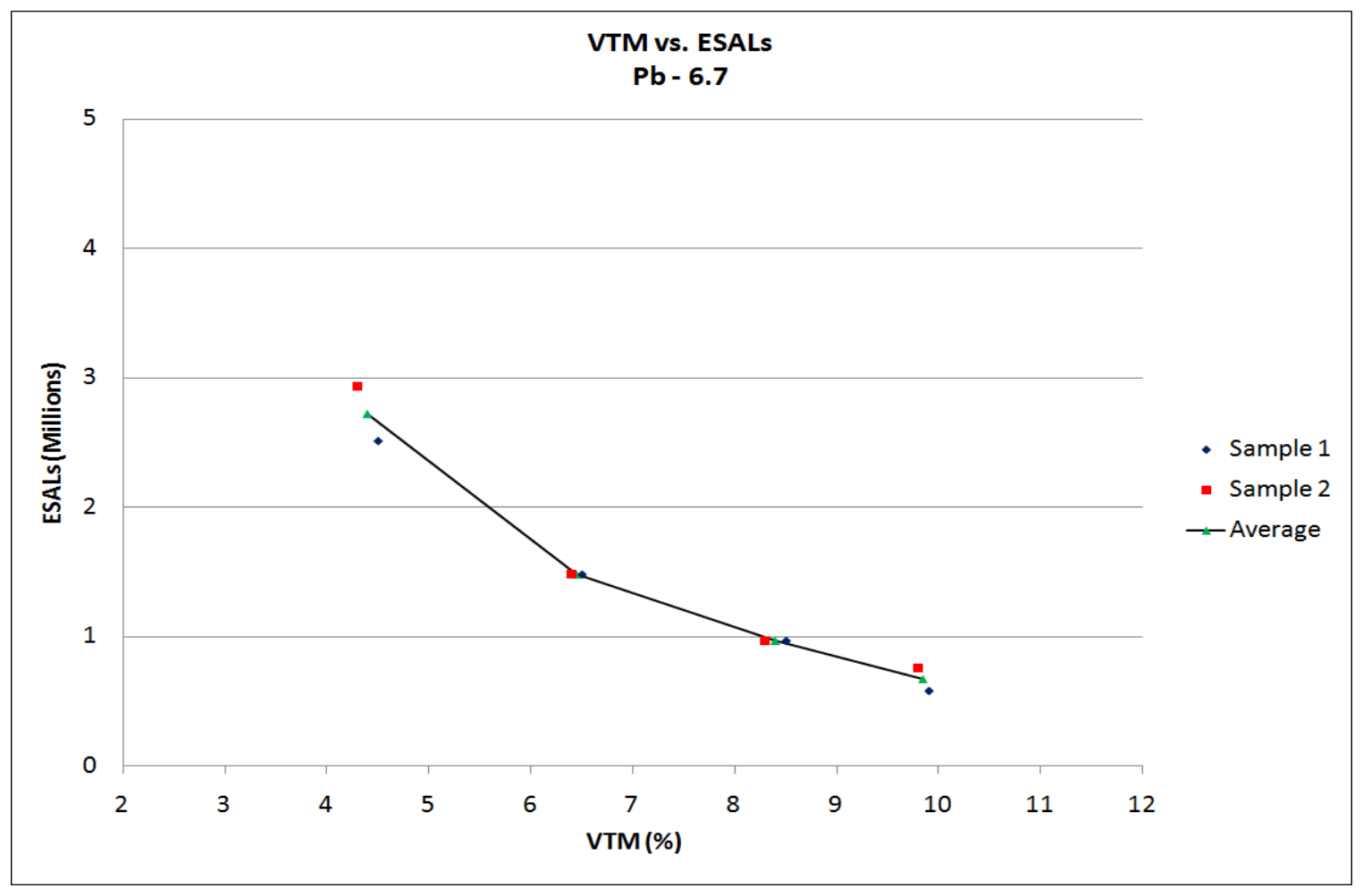

Figure 4.15: Estimated Maximum Allowable Traffic at 6.7 Percent Binder

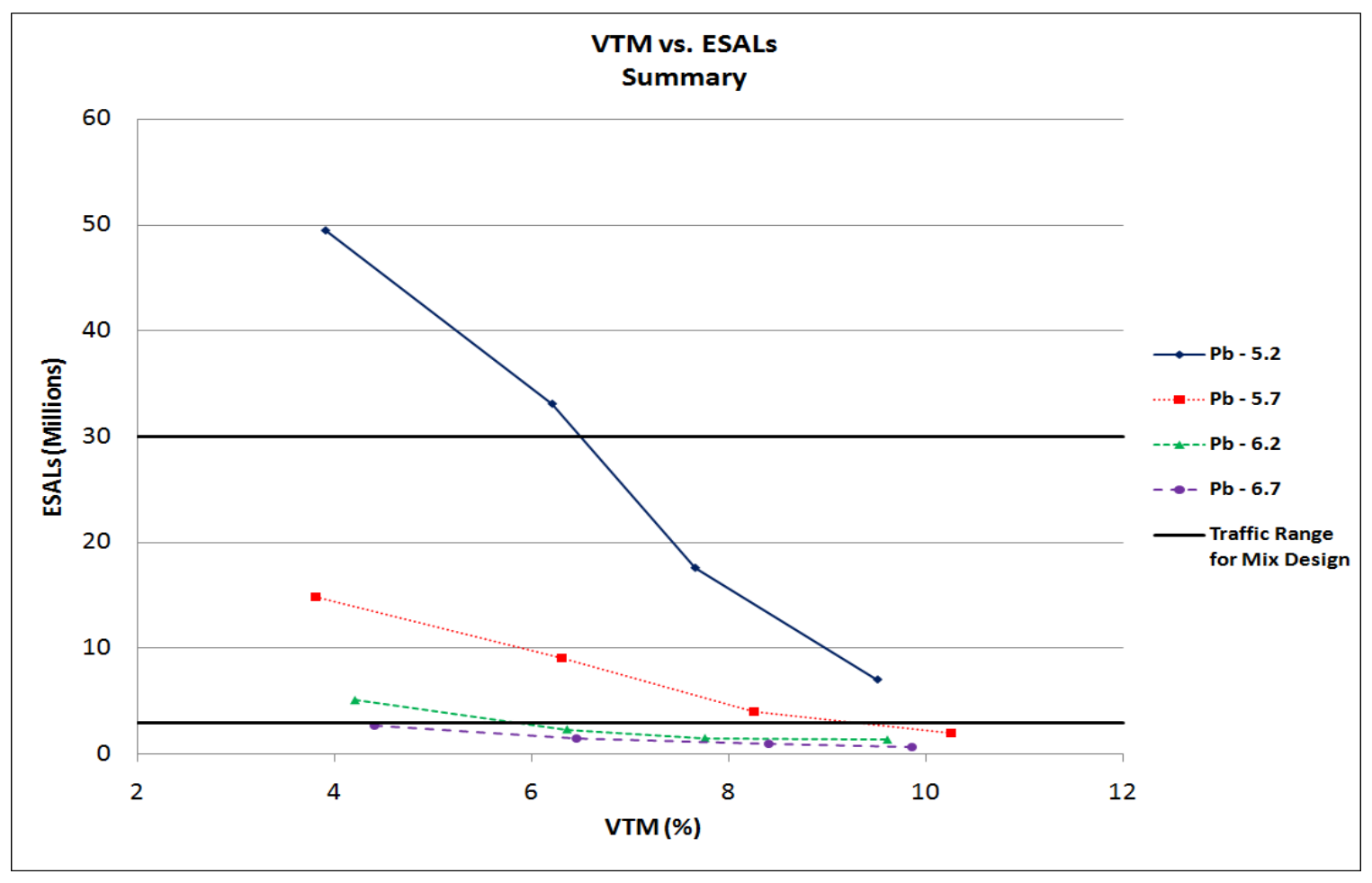

Figure 4.16: Summary of Average Estimated Maximum Allowable Traffic 


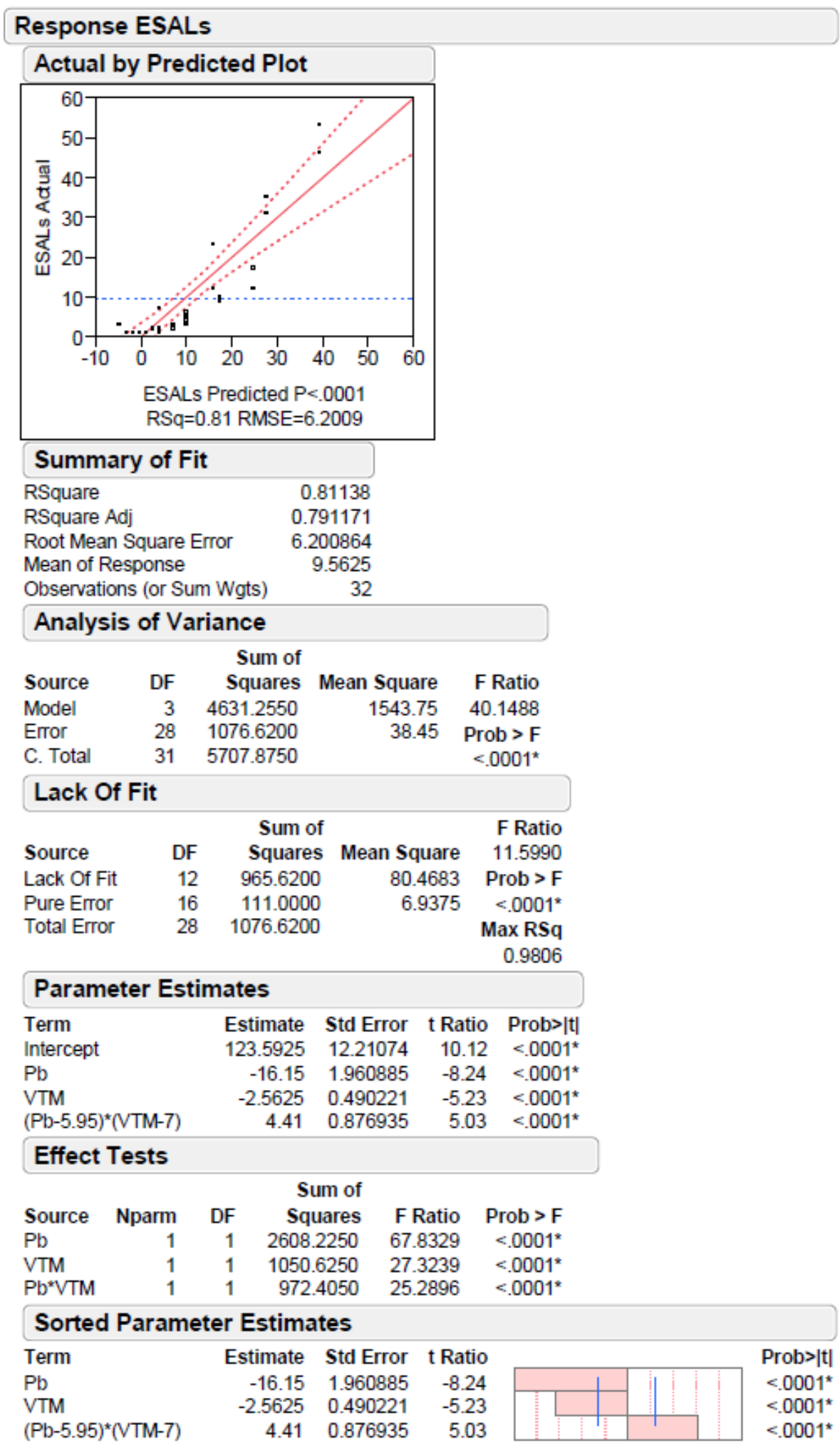

Figure 4.17: IDT Statistical Analysis Results 


\section{CHAPTER 5: CONCLUSIONS AND RECOMMENDATIONS}

\subsection{CONCLUSIONS}

The gyratory data gathered from this research confirms that the number of gyrations needed to compact a sample to a desired height is reduced when increasing the amount of binder in a mixture. This principle also applies when compacting a pavement to a specified density. The number of passes a roller is required to make is reduced by increasing the amount of binder in a mixture, although, if excessive amounts of binder are used, the likelihood of rutting is greatly enhanced.

The permeability data gathered from this research confirms that when increasing air void levels, permeability is shown to increase as expected. Also, when the amount of binder is increased, it fills the available air voids and decreases permeability. Results verify that permeability remains almost constant from 4 to 7 percent air void content. Permeability is shown to drastically increase at 8 percent air void content and above. The statistical analysis performed verifies this result and concludes that both binder content and air void levels significantly affect permeability.

The indirect tension (IDT) strength data gathered from this research confirms that when increasing binder content, rutting resistance decreases. The mix design used in this research had an ESAL range of 3 to 30 million. Samples containing 5.2 and 5.7 percent binder stayed within this range from 4 to 8 percent air content. Samples containing 6.2 and 6.7 percent binder fell below the minimum ESAL range from 5 to 10 percent air void content. The statistical analysis performed verifies the results of this test. Both binder content and air void levels are shown to significantly affect rutting resistance.

\subsection{RECOMMENDATIONS}

Permeability testing using the Florida Method of Test proved to be an easy and effective way to test the permeability of compacted hot mix asphalt samples. This research consisted of only three aggregate types, one nominal maximum aggregate size (NMAS), and one gradation. Further research is required to fully understand the effects of binder content on permeability. 
Multiple NMAS and gradations, both coarse and fine, should be tested. Also, more aggregate types such as crushed aggregates, slag, and various types of sand should be tested. Since this test proved to be both cost and time effective, permeability testing should be included as part of the mix design process.

The results of the permeability research show that asphalt becomes permeable when air voids reach approximately 8 percent. Current WVDOH specifications state that asphalt air void contents must be between 4 and 8 percent. Changing maximum air void content specification from 8 to 7 percent should decrease the possibility for pavements to reach the threshold where permeability drastically increases.

The state has issued a supplemental specification, effective for the 2010 construction season, which should promote increased binder content of SuperPave mixtures. This should improve the compactibility and long term durability of the mixtures. However, the rutting resistance of the mixtures may be compromised. Samples of mixtures used during the 2010 construction season should be sent to the West Virginia University Asphalt Technology Laboratory for rutting evaluation. 


\section{REFERENCES}

Brown, E. R., Collins, R., and Brownfield, J. R. "Investigation of Segregation of Asphalt Mixtures in the State of Georgia" Transportation Research Record 1217, TRB, National Research Council, Washington, DC, 1989.

Christensen, D., Bonaquist, R. "Using the Indirect Tension Test to Evaluate Rut Resistance in Developing Hot-Mix Asphalt Mix Designs" Advanced Asphalt Technologies, 2007.

Cooley, Jr., L. A. "Permeability of SuperPave Mixtures: Evaluation of Field Parameters" NCAT Report 99-1, February 1999.

Cooley, Jr., L. A., Prowell, B., and Brown, E. R. "Issues Pertaining to the Permeability Characteristics of Coarse-Graded SuperPave Mixes" NCAT Report 02-06, July 2002.

"Factors Affecting HMA Permeability" February 2005. <http://www.wsdot.wa.gov/biz/mats/Pavement/TechNotes/FactorsAffectingHMA PermeabilityTN2007.pdf> (June 5, 2009)

Florida Department of Transportation "Florida Method of Test for Measurement of Water Permeability of Compacted Asphalt Paving Mixtures" December 27, 2004.<http://www.qcqa.com/docs/doc_238.pdf> (June 5, 2009)

Ford, M. C., and McWilliams, C. E. "Asphalt Mix Permeability" University of Arkansas, Fayettville, AR, 1988.

Gogula, A., Hossain, M., and Romanoschi, S. "A Study of Factors Affecting the Permeability of SuperPave Mixes in Kansas", Final Report. Technical Report KSU-00-2, November 2004.

Hudson, S. B., and Davis, R. L. "Relationship of Aggregate Voidage to Gradation" Association of Asphalt Paving Technologists, Volume 34. 1965.

Kandhal, P., Rickards, I. "Premature Failure of Asphalt Overlays From Stripping: Case Histories" NCAT Report 01-01, April 2001.

Mallick, R. B., Cooley, Jr., L. A., and Teto, M., Bradbury, R., Peabody, D. “An Evaluation of Factors Affecting Permeability of SuperPave Designed Pavements" NCAT Report 03-02, June 2003.

Mallick, R. B., Cooley, Jr., L. A., and Teto, M. "Evaluation of Permeability of SuperPave Mixes in Maine", Final Report. Technical Report ME-001, November 1999. 
Maupin, Jr., G. W. "Investigation of Test Methods, Pavements, and Laboratory Design Related to Asphalt Permeability", Final Report. Technical Report VTRC 00- R24, June 2000.

Mohammad, L., Herath, A., and Huang, B. "Evaluation of Permeability of SuperPave Asphalt Mixtures" TRB 2003 Annual Meeting CD-ROM

Musselman, J. A., Choubane, B., Page, G. C., and Upshaw, P. B. "SuperPave Field Implementation: Florida's Early Experience" Transportation Research Record 1609, 1998.

"Porosity and Permeability" World of Earth Science. Ed. K. Lee Lerner and Brenda Wilmoth Lerner. Gale Cengage, 2003. eNotes.com. 2006.

$<$ http://www.enotes.com/earth-science/porosity-permeability> (June 5, 2009)

Roberts, F. L., Kandhal, P. S., Brown, E. R., Lee, D. Y., and Kennedy, T. W. "Hot Mix Asphalt Materials, Mixture Design, and Construction" NAPA Education Foundation, Lanham, MD. Second Ed., 1996.

Russell, J. S., Bahia, H. U., Kanitpong, K., Schmitt, R. L., and Crovetti, J. C. "The Effect of Pavement Thickness on SuperPave Mix Permeability and Density", Final Report. Project 0092-04-02c, Wisconsin Department of Transportation, Wisconsin Highway Research Program, Madison, WI, 2004.

"SuperPave Construction Guidelines" National Asphalt Pavement Association. Special Report 180. Lanham, Maryland. October 1997.

Zaniewski, J.P., Adams, T. "Evaluation of Quality Control Parameters for SuperPave Hot Mix Asphalt”'WVODH Reports. Asphalt Technology Program, 2005

Zube, E., "Compaction Studies of Asphalt Concrete Pavements as Related to the Water Permeability Test" Highway Research Board, Bulletin 358, TRB, National Research Council, Washington, DC, 1962. 